\title{
A Novel Fuzzy PI-LADRC Combined Control Strategy for Permanent Magnet Synchronous Motorized Spindle
}

Shan Wentao ( $\sim$ shanwentao520@163.com )

Jiangsu University of Technology https://orcid.org/0000-0003-4171-3106

Zhiheng Yun

Jiangsu University of Technology

Guomeng Bai

Jiangsu University of Technology

Original Article

Keywords: Permanent magnet synchronous motorized spindle, Fuzzy PI control, Active disturbance rejection control, Vector control, Dynamic response

Posted Date: June 2nd, 2021

DOl: https://doi.org/10.21203/rs.3.rs-520970/v1

License: (c) (1) This work is licensed under a Creative Commons Attribution 4.0 International License. Read Full License 


\title{
A novel fuzzy PI-LADRC combined control strategy for permanent magnet synchronous motorized spindle
}

\author{
Wen-tao SHAN*, Zhi-heng YUN* and Guo-meng BAI* \\ *Jiangsu University of Technology \\ ZhongWu Road 1801, ChangZhou, 213001, China \\ E-mail: shanwentao520@163.com
}

\begin{abstract}
This paper focuses on the vector control scheme of surface-mounted permanent magnet synchronous motorized spindle, to solve the problem of poor speed regulation performance of spindle under high-speed operation conditions, according to the principle of double closed-loop vector control, the characteristics of speed loop and current loop are analyzed, and fuzzy theory is introduced to optimize the traditional speed loop PI controller, furthermore the system parameters are adjusted in real time. Aiming at improving the dynamic response ability of the control system, a first-order linear active disturbance rejection controller is proposed to replace the traditional current loop PI controller, which enhances the anti-interference ability of the system. Experimental results show that the fuzzy PI-LADRC combined control strategy can effectively reduce stator current ripple and torque ripple, and improve the dynamic response speed and anti-interference ability of the system. At last can also improve the output performance of the motorized spindle.
\end{abstract}

Keywords: Permanent magnet synchronous motorized spindle, Fuzzy PI control, Active disturbance rejection control, Vector control, Dynamic response

\section{Introduction}

High-speed motorized spindle is the core of high-speed machine tool, which is a transmission structure combining spindle and motor. Motorized spindle has the advantages of compact structure, light weight, high mechanical efficiency, low vibration, low noise and high precision [1]. The development of high-speed motorized spindle has greatly promoted the development of high-speed machining technology in the world. In recent years, with the development of modern control theory and artificial intelligence, intelligent control has been widely used in motorized spindle control technology. To further improve the machining accuracy and stability of permanent magnet synchronous motorized spindle under high-speed operation conditions, it is necessary to have a deeper study on the driving technology of motorized spindle.

Nowadays, vector control is widely used. id $=0$ control is a kind of vector control, its essence is to realize $\mathrm{d}-\mathrm{q}$ axis current decoupling, and the control process is relatively simple. The speed loop and current loop of traditional id $=0$ control strategy is PID controllers, which are simple in principle and convenient to use, but there will be problems such as large current fluctuation, large torque ripple and poor robustness in the control process. Therefore, the performance of the speed loop and the current loop directly affects the control effect of the speed control system. Therefore, it is the key to seek a better control strategy. Reference [2] proposes active disturbance rejection control technology (ADRC). Based on the advantages of PID, an extended disturbance observer is designed to observe and compensate disturbances in real time, which enhances the anti-disturbance ability of the system. However, the introduction of nonlinear functions leads to too difficult parameter tuning. References [3-5] optimizes the active disturbance rejection control technology and applies it to synchronous motors, but it still does not solve the problem of difficult parameter adjustment of nonlinear functions. In reference [6], the idea of bandwidth is introduced, and linear active disturbance rejection control (LADRC) is proposed, which greatly simplifies the parameter tuning. Reference [7] proposes a control strategy based on BP neural network. The strategy has strong nonlinear information processing capability and does not depend on the external model of the system, thus improving the robustness of the system, but it has some shortcomings such as slow convergence speed and local minimum. Reference [8] proposes a terminal sliding mode control strategy, which enables nonlinear sliding mode to replace traditional linear sliding mode. It has a fast-dynamic response to the system and can quickly approach the target value, but it still brings chattering problems. 
At present, fuzzy control and active disturbance rejection control are widely used in motor drive, and each has its own advantages and disadvantages. Considering that a single control mode cannot meet the control requirements of motorized spindle. Based on the $\mathrm{id}=0$ control mode of permanent magnet synchronous motorized spindle (PMSMS), a fuzzy PI-LADRC combined drive strategy is proposed in this paper. Combining the advantages of the two kinds of control, the speed loop and the current loop are designed respectively, so that the current fluctuation of the system is small, the torque ripple is reduced, the anti-interference ability is enhanced, and the control performance is greatly improved. The correctness and effectiveness of this method are verified by experimental simulation.

\section{PMSMS mathematical model}

Due to the complex electromagnetic relationship between stator winding and rotor permanent magnet of permanent magnet synchronous motorized spindle, and the influence of many nonlinear factors, it is impossible to accurately establish the model. Therefore, to describe the mathematical model of permanent magnet synchronous motorized spindle more accurately, the following assumptions are usually made [9]:

(1) Regardless of eddy current loss and hysteresis loss, ignoring core magnetoresistance;

(2) The permeability in the permanent magnet is approximately the value of air;

(3) No damping winding on the rotor;

(4) The stator windings inside the motorized spindle are completely symmetrical, and the magnetic field waveform generated by induction is sinusoidal with the excitation magnetic field generated by permanent magnets;

(5) When the motorized spindle is in a steady state, the induced potential in the stator winding of the spindle is a sine wave;

The voltage and flux linkage equations of surface mounted permanent magnet synchronous generator in d-q rotating coordinate system are expressed as:

$$
\begin{aligned}
& \left\{\begin{array}{l}
u_{q}=R_{s} i_{q}+\dot{\psi}_{q}-\omega \psi_{q} \\
u_{d}=R_{s} i_{d}+\dot{\psi}_{d}-\omega \psi_{d}
\end{array}\right. \\
& \left\{\begin{array}{l}
\psi_{q}=L_{q} i_{q}+\psi_{f} \\
\psi_{d}=L_{d} i_{d}
\end{array}\right.
\end{aligned}
$$

The electromagnetic torque and motion equation are:

$$
\begin{gathered}
\left\{\begin{array}{l}
u_{q}=R_{s} i_{q}+\dot{\psi}_{q}-\omega \psi_{q} \\
u_{d}=R_{s} i_{d}+\dot{\psi}_{d}-\omega \psi_{d}
\end{array}\right. \\
\left\{\begin{array}{l}
\psi_{q}=L_{q} i_{q}+\psi_{f} \\
\psi_{d}=L_{d} i_{d}
\end{array}\right.
\end{gathered}
$$

For the surface-mounted permanent magnet synchronous electric spindle, the formula $L_{q}=L_{d}(2.3)$ is simplified as :

$$
T_{e}=\frac{3}{2} n_{p} \psi_{f} i_{q}
$$

Where: $u_{q}, u_{d}, i_{q}, i_{d}, \Psi_{q}, \Psi_{d}, L_{q}, L_{d}$ are the voltage, current, flux linkage, and inductance of the stator winding $q$ - $d$ axis; $\Psi_{f}$ is the fundamental flux linkage of the excitation magnetic field generated by the rotor permanent magnet inside the electric spindle; $R_{s}$ is the stator resistance; $T_{e}$ is the electromagnetic torque; $B$ is the viscous friction coefficient; $J$ is the moment of inertia on the electric spindle rotor, including the applied load; $\omega_{m}$ is the rotor mechanical angular velocity; $T_{L}$ is the load torque.

\section{Design of speed loop controller}


As the outer loop of the high-speed motorized spindle control system, the speed loop realizes speed control, which is the core link in the control system and should have the characteristics of high precision, fast response and wide speed regulation range. In actual control, PI speed regulator is generally used to control the speed loop. This control scheme is simple and easy to realize, which makes the system obtain better steady-state accuracy. Conventional PI control is shown in Figure 1. However, due to the nonlinear and strong coupling characteristics of permanent magnet synchronous motorized spindle and the large torque fluctuation under high-speed operation conditions, the rapidity and robustness of the system to parameter fluctuation are not rational enough. To solve these problems, fuzzy theory [10] is combined with traditional PI control, and an adaptive fuzzy PI controller is constructed to replace the traditional speed loop PI controller.

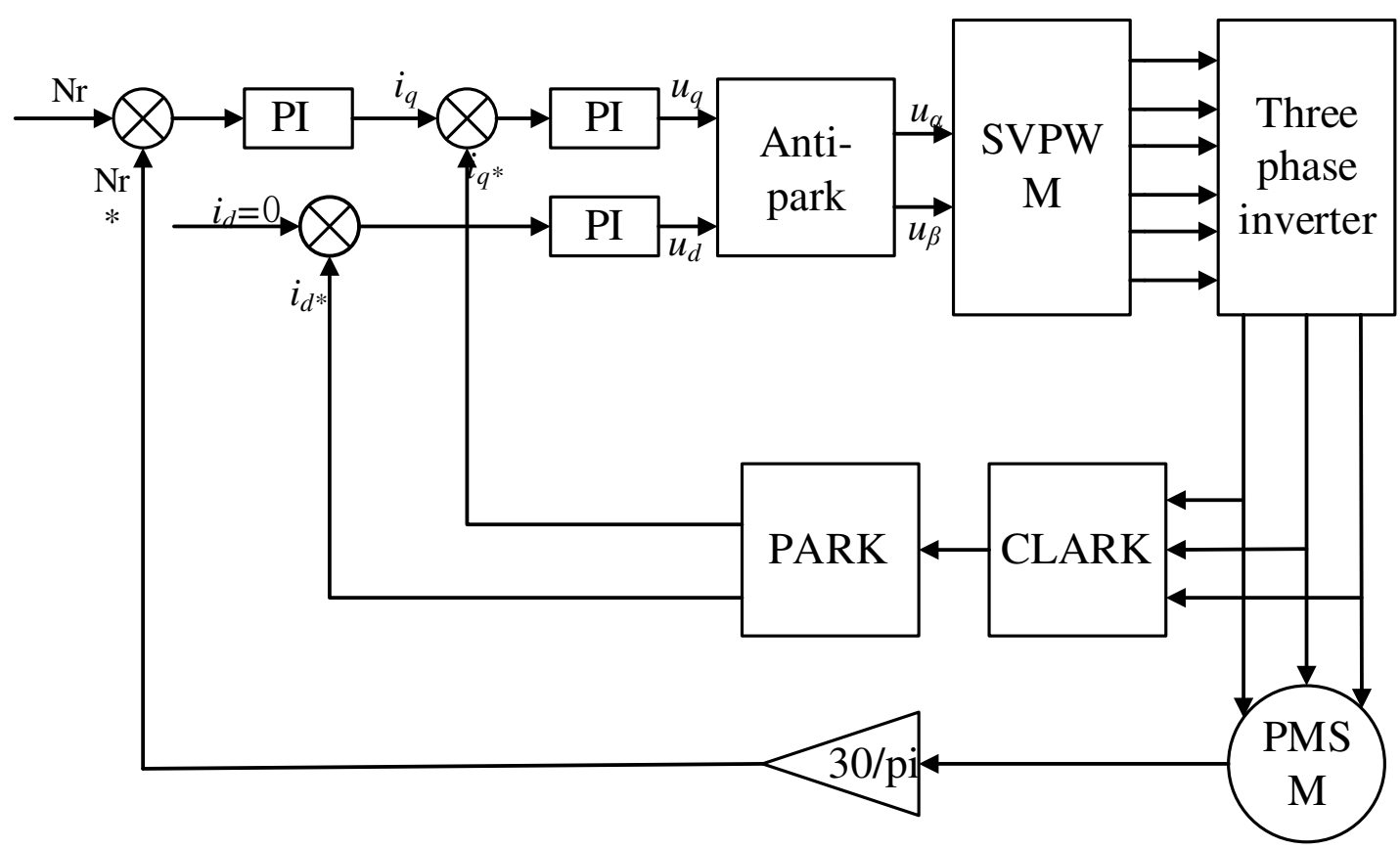

Figure. 1 Traditional PI control system block diagram

\subsection{Establishment and selection of membership function}

Selecting the appropriate fuzzy membership function [11] can obtain better control parameters. The establishment process of membership function is not subjective, so the determination of this function is generally based on the conclusion of big data statistics and the conclusion given by experts in this field. The common distribution forms of membership degree are triangle, normal type, above-ring type and below-ring type. Considering that the sharper the shape of membership function curve, the higher the resolution and the higher the control sensitivity. In this paper, triangle is selected as the membership function of input and output. The membership function of a triangle is expressed as:

$$
\mu(x)=\left\{\begin{array}{l}
\frac{2(x-a)}{b-a}, x \in\left[a, \frac{a+b}{2}\right] \\
\frac{2(x-a)}{a-b}, x \in\left[\frac{a+b}{2}, b\right]
\end{array}\right.
$$

\subsection{Design of fuzzy controller}

In the design process of fuzzy controller [12], a set of fuzzy structures can be obtained by fuzzifying the input quantity, and the optimal adjustment of PI parameters can be automatically realized after anti-fuzzification.

The speed error $e$ and the error rate of change $e c$ are expressed as: 


$$
\left\{\begin{array}{l}
e(k)=\omega^{*}(k)-\omega(k-1) \\
e_{c}(k)=\frac{e(k)-e(k-1)}{T}
\end{array}\right.
$$

In the formula, $\omega^{*}(k)$ is the speed reference signal of the kth sampling cycle; $\omega(k-1)$ is the speed feedback signal of the k-1 th sampling cycle; $e(k)$ and $e(k-1)$ are the rotational speed error of the $k$ th and $k$ - 1 th sampling period respectively; $e c(\mathrm{k})$ is the error change rate of the kth sampling period; $T$ is the sampling period. The time domain expression of traditional PI controller is as follows:

$$
u(t)=k_{p i} e(t)+\frac{1}{\tau} \int e(t) d t=k_{p} e(t)+k_{i} \int e(t) d t
$$

In the formula, $k_{p}, k_{p i}$ are proportional coefficients, and their values are equal; $k_{i}=1 / \tau$ is the integral coefficient. According to the above situation, the fuzzy control structure is established as shown in Figure 2.

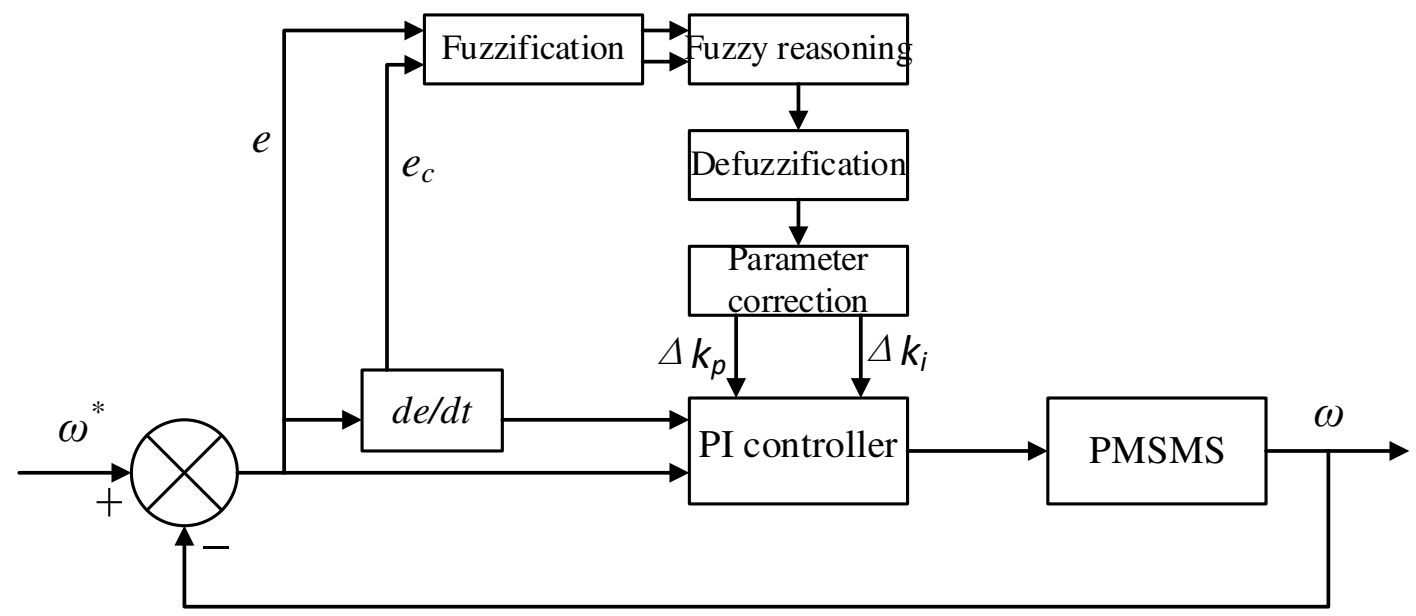

Figure. 2 Structure block diagram of fuzzy controller

As can be seen from Figure 2, the input quantities of $e$ and $e c$, the adjustment quantities $\Delta k_{p}$ and $\Delta k_{i}$ are the output quantities. The dynamic and static performance of the system can be improved by adjusting $\Delta k_{p}$ and $\Delta k_{i}$ online by fuzzy controller. The specific steps of solving the fuzzy controller are as follows.

The real-time error e and error variation $e c$ of the preset value and feedback value of the motorized spindle speed are taken as input quantities, and the quantization level is 7 , namely $\{-3,-2,-1,0,1,2,3\}$, the domain of real-time error e and error change $e c$ are both [-10000,10000]. The two parameters of the regulator $\Delta k_{p}$ and $\Delta k_{i}$ are used as the output, so that they are also quantified to the above seven levels. The domains of the output of $\Delta k_{p}$ and $\Delta k_{i}$ are [-2,2] and [-1,1], respectively, which are all subject to triangle membership Degree distribution curve. The instantaneous error e of the rotational speed, its error change $e c$, and the membership functions of $\Delta k_{p}$ and $\Delta k_{i}$ are shown in Figure 3, and the membership functions of the fuzzy set are shown in Table 1.

The fuzzy logic decision is composed by Max-Min of Mamdani algorithm. The fuzzy controller first fuzzifiers the input quantities, then carries out fuzzy reasoning on the fuzzified data according to certain fuzzy rules, and then seeks the rule table in the fuzzy rule base to adjust the parameters in real time.

The process of transforming the fuzzy quantity obtained by fuzzy rule reasoning into a certain value. When appropriate models are used, fuzzification steps can be saved. However, when Mamdani model is used for reasoning, there are two mapping methods: one is the maximum membership method, and the other is the center of gravity method. The former can directly solve the fuzzy quantity and average multiple extremum values of the output result. The latter is a common method to solve fuzzification at present, and the output result is the closed area surrounded by the function curve and $\mathrm{X}$ and $\mathrm{Y}$ coordinate axes. The mapping method used in this paper is the center of gravity method: 


$$
\Delta \hat{u}(t)=\frac{\sum_{k=1}^{n} b_{k} \int_{\Delta u_{k}} \mu_{\Delta u_{k}}^{\prime}(\Delta u) d \Delta u}{\sum_{k=1}^{n} \int_{\Delta u_{k}} \mu_{\Delta u_{k}}^{\prime}(\Delta u) d \Delta u}
$$

Where $\Delta \hat{\mu}(t)$ is the anti-fuzzification output, $n$ is the total number of rules of the fuzzy controller, $b_{k}$ is the regional center of the corresponding output membership function, and $\int_{\Delta u_{k}} \mu_{\Delta u_{k}}^{\prime}(\Delta u) d \Delta u$ is the area surrounded by the output membership function.

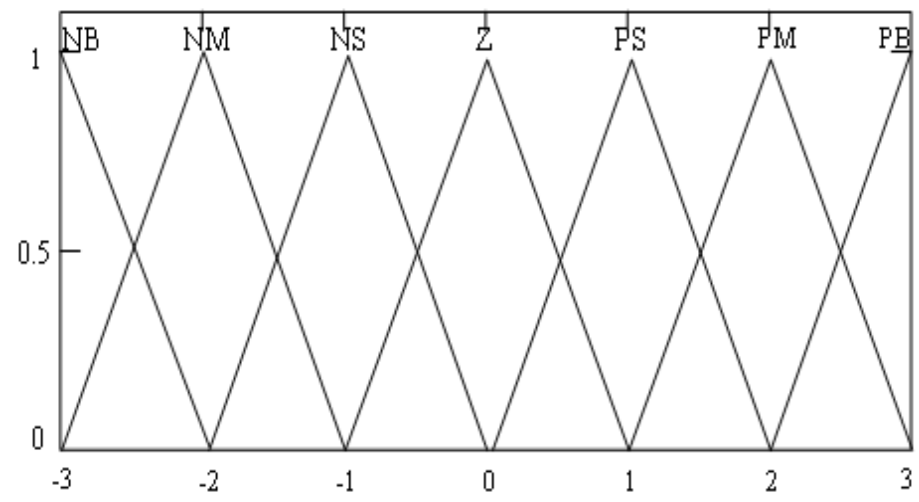

Figure. 3 Membership function diagram

Table 1 Membership function of fuzzy sets

\begin{tabular}{c|c|c|c|c|c|c|c}
\hline$e \times 10^{4}$ & -1 & -0.67 & -0.33 & 0 & 0.33 & 0.67 & 1 \\
\hline$e_{\mathrm{c}} \times 10^{4}$ & -1 & -0.67 & -0.33 & 0 & 0.33 & 0.67 & 1 \\
\hline$\Delta k_{\mathrm{p}}$ & -2 & -1.33 & -0.67 & 0 & 0.67 & 1.33 & 2 \\
\hline$\Delta k_{\mathrm{i}}$ & -1 & -0.67 & -0.33 & 0 & 0.33 & 0.67 & 1 \\
\hline Quantitative level & -3 & -2 & -1 & 0 & 1 & 2 & 3 \\
\hline
\end{tabular}

The fuzzy PI controller calculates the rotational speed fed back by the motorized spindle with the given value of the system in real time, and obtains the rotational speed error $e$ and the rotational speed error change rate $e c$ required by the fuzzy controller. Then, the fuzzy rules proposed above are used to make fuzzy reasoning on the speed error $e$ and the speed error change rate $e c$, and finally the fuzzy matrix table is queried for parameter adjustment.

The fuzzy rule table for $\Delta k_{p}$ setting is shown in Table 2, and the fuzzy rule table for $\Delta k_{i}$ setting is shown in Table 3 .

Table 2 Fuzzy rule table of $\Delta k_{p}$

\begin{tabular}{|c|c|c|c|c|c|c|c|c|}
\hline \multirow{2}{*}{$\Delta k$} & & \multicolumn{7}{|c|}{$e$} \\
\hline & & \multirow{2}{*}{$\begin{array}{l}\mathrm{NB} \\
\mathrm{PB}\end{array}$} & \multirow{2}{*}{$\begin{array}{l}\mathrm{NM} \\
\mathrm{PB}\end{array}$} & \multirow{2}{*}{$\begin{array}{l}\mathrm{NS} \\
\mathrm{PM}\end{array}$} & \multirow{2}{*}{$\frac{Z}{\mathrm{PM}}$} & \multirow{2}{*}{$\begin{array}{l}\text { PS } \\
\text { PS }\end{array}$} & \multirow{2}{*}{$\frac{\mathrm{PM}}{\mathrm{PM}}$} & \multirow{2}{*}{$\begin{array}{l}\mathrm{PB} \\
\mathrm{Z}\end{array}$} \\
\hline \multirow{7}{*}{$e_{c}$} & $\mathrm{NB}$ & & & & & & & \\
\hline & $\mathrm{NM}$ & PB & PB & $\mathrm{PM}$ & $\mathrm{PM}$ & PS & $\mathrm{Z}$ & $\mathrm{Z}$ \\
\hline & NS & $\mathrm{PM}$ & PM & $\mathrm{PM}$ & PS & $\mathrm{Z}$ & NS & $\mathrm{NM}$ \\
\hline & $\mathrm{Z}$ & $\mathrm{PM}$ & PS & PS & Z & NS & NM & $\mathrm{NM}$ \\
\hline & PS & PS & PS & $\mathrm{Z}$ & NS & NS & NM & NM \\
\hline & $\mathrm{PM}$ & $\mathrm{NM}$ & $\mathrm{Z}$ & NS & $\mathrm{NM}$ & NM & NM & NB \\
\hline & PB & $\mathrm{Z}$ & NS & NS & NM & NM & NB & NB \\
\hline
\end{tabular}


Table 3 Fuzzy rule table of $\Delta k_{i}$

\begin{tabular}{|c|c|c|c|c|c|c|c|c|}
\hline \multirow{2}{*}{$\Delta k_{i}$} & & \multicolumn{7}{|c|}{$e$} \\
\hline & & NB & $\mathrm{NM}$ & NS & $Z$ & PS & $\mathrm{PM}$ & PB \\
\hline \multirow{7}{*}{$e_{c}$} & NB & PS & PS & $\mathrm{Z}$ & $Z$ & $\mathrm{Z}$ & PB & PB \\
\hline & NM & NS & NS & NS & NS & $Z$ & NS & PM \\
\hline & NS & NB & NB & NM & NS & Z & PS & PM \\
\hline & Z & NB & NM & NM & NS & $\mathrm{Z}$ & PS & PM \\
\hline & PS & NM & $\mathrm{NM}$ & NS & Z & Z & PS & PS \\
\hline & PM & NM & NS & NS & Z & Z & PS & PS \\
\hline & PB & PS & Z & Z & Z & Z & PB & PB \\
\hline
\end{tabular}

The fuzzy PI control block diagram is shown in Figure 4 as follows :

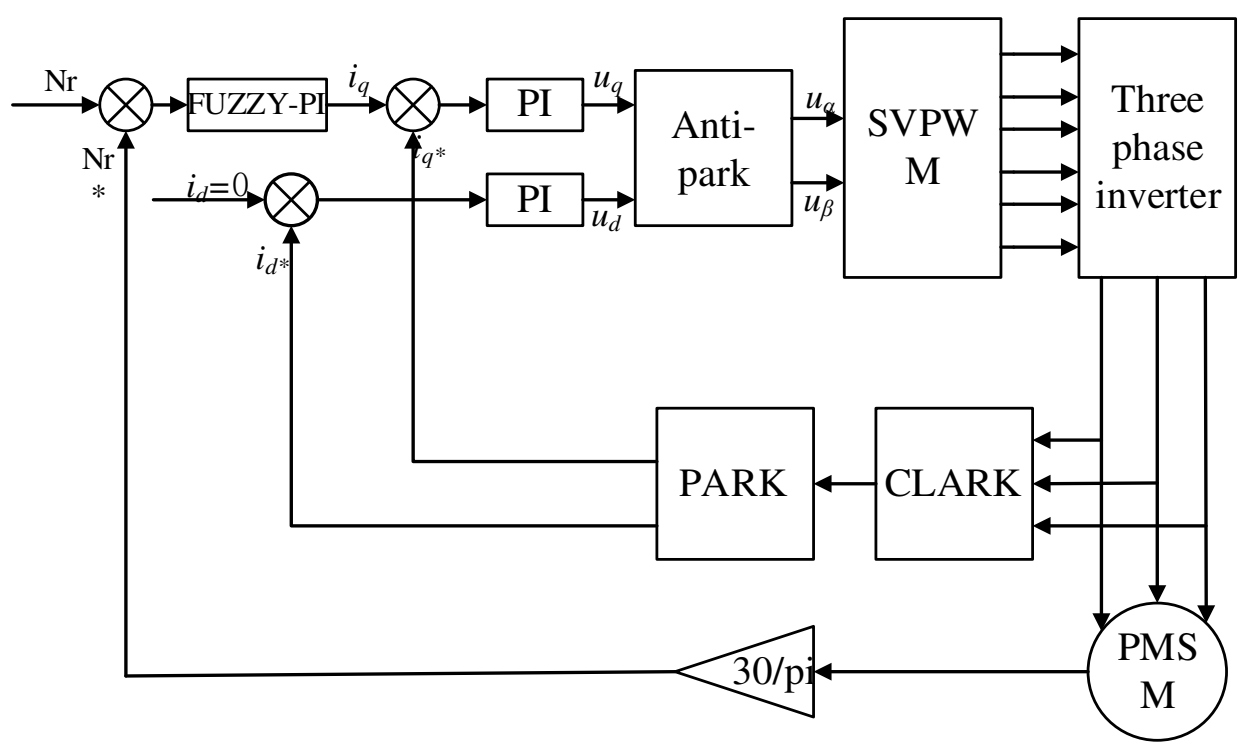

Figure. 4 Fuzzy PI control system block diagram

\section{Design of current loop controller}

As the inner loop of the control system, the current loop is used to track the stator current accurately and quickly, and its control effect directly determines the control performance of the speed loop, which plays a great role in the whole control system. The control mode id $=0$ is selected for decoupling control, and the control process is simple. However, when PI controller is generally used, there will be some problems such as large current fluctuation and insufficient anti-interference ability. To solve the negative effects of PI control, a linear active disturbance rejection controller (LADRC) is designed to replace the traditional current loop PI controller [13].

\subsection{Design of LADRC controller}

The traditional linear active disturbance rejection controller is composed of linear tracking differentiator (LTD), linear extended state observer (LESO) and linear state error feedback (LESF). Considering the design of the current loop controller, it can be seen from equation (1.1) that the $q$ - $d$ axis input current and output voltage present a first-order linear relationship [14], so a first-order linear active disturbance rejection controller is designed. Because the current loop is in the inner loop of the control system, the current change speed is continuously changing. In order not to cause unnecessary phase lag and considering the simplicity and usability of the design principle, LTD can be omitted. 
The function of LESO is to observe the state quantity and disturbance quantity and rewrite the $q$ - $d$ axis voltage equation:

$$
\left\{\begin{array}{l}
u_{q}=R_{s} i_{q}+\dot{\psi}_{q}-\omega \psi_{q} \\
u_{d}=R_{s} i_{d}+\dot{\psi}_{d}-\omega \psi_{d}
\end{array}\right.
$$

Rewrite the voltage equation:

$$
\left\{\begin{array}{l}
u_{q}=R_{s} i_{q}+L_{q} \frac{\mathrm{d} i_{q}}{\mathrm{~d} t}+\omega_{e} L_{d} i_{d}+\omega_{e} \psi_{f} \\
u_{d}=R_{s} i_{d}+L_{d} \frac{\mathrm{d} i_{d}}{\mathrm{~d} t}-\omega_{e} L_{q} i_{q}
\end{array}\right.
$$

Further rewritten to:

$$
\left\{\begin{array}{l}
\frac{\mathrm{d} i_{q}}{\mathrm{~d} t}=\frac{1}{L_{q}}\left(u_{q}-R_{s} i_{q}-\omega_{e} L_{d} i_{d}-\omega_{e} \psi_{f}\right)=f_{i q}+b_{x} u_{q} \\
\frac{\mathrm{d} i_{d}}{\mathrm{~d} t}=\frac{1}{L_{d}}\left(u_{d}-R_{s} i_{d}+\omega_{e} L_{q} i_{q}\right)=f_{i d}+b_{y} u_{d}
\end{array}\right.
$$

Where $f_{i d}$ and $f_{i q}$ are generalized total disturbances, $b_{x}$ and $b_{y}$ are estimated control gain, and:

$$
\begin{aligned}
& f_{i q}=\frac{u_{q}-R_{s} i_{q}-\omega_{e} L_{q} i_{q}-\omega_{e} \psi_{f}}{L_{q}}-b_{x} u_{q} \\
& f_{i d}=\frac{\left(u_{d}-R_{s} i_{d}+\omega_{e} L_{q} i_{q}\right)}{L_{d}}-b_{x} u_{d}
\end{aligned}
$$

It can be seen from the above formula that the LADRC design of the $d-q$ axis is the same, the difference is the amount of disturbance and the selection of $b_{x, y}$, so the $q$-axis current loop is taken as an example to design LDARC [15], then:

$$
\dot{i}_{q}=f_{i q}+b_{x} u_{q}
$$

Making $y=x_{1}=i_{q}, \quad x_{2}=f_{i q}$

The above equation is written as the following state space equation:

$$
\left\{\begin{array}{l}
\dot{x}_{1}=x_{2}+b_{x} u_{q} \\
\dot{x}_{2}=f_{i q} \\
y=i_{q}
\end{array}\right.
$$

According to the construction principle of the linear active disturbance rejection controller, the mathematical model of LESO is established: 


$$
\left\{\begin{array}{l}
e=i_{q}-z_{1} \\
\dot{z}_{1}=z_{2}+b_{x} u_{q}+\beta_{1} e \\
\dot{z}_{2}=\beta_{2} e
\end{array}\right.
$$

In the formula: $z_{1}$ is the output current observation value; $z_{2}$ is the output disturbance observation value; $\beta_{1}$ and $\beta_{2}$ are adjustable parameters.

Linear error feedback (LESO) is mainly used to eliminate disturbances. According to formula (4.6), it can be known that $b_{x} i_{q}=u-\mathrm{Z}_{2}$ should be selected to offset the influence of current loop disturbance, and formula (4.6) is expressed as:

$$
\dot{i}_{q}=u+f_{i q}-z_{2} \approx u
$$

After disturbance compensation, the current loop is equivalent to an integral link. The linear disturbance compensation control law is designed as follows: $u=K\left(i_{q^{*-}} \mathrm{Z}_{1}\right)$, where $i_{q^{*}}$ is the rated input current and $K$ is the proportional gain.

The current loop $q$-axis LADRC structure is shown in Figure 5 as follows:

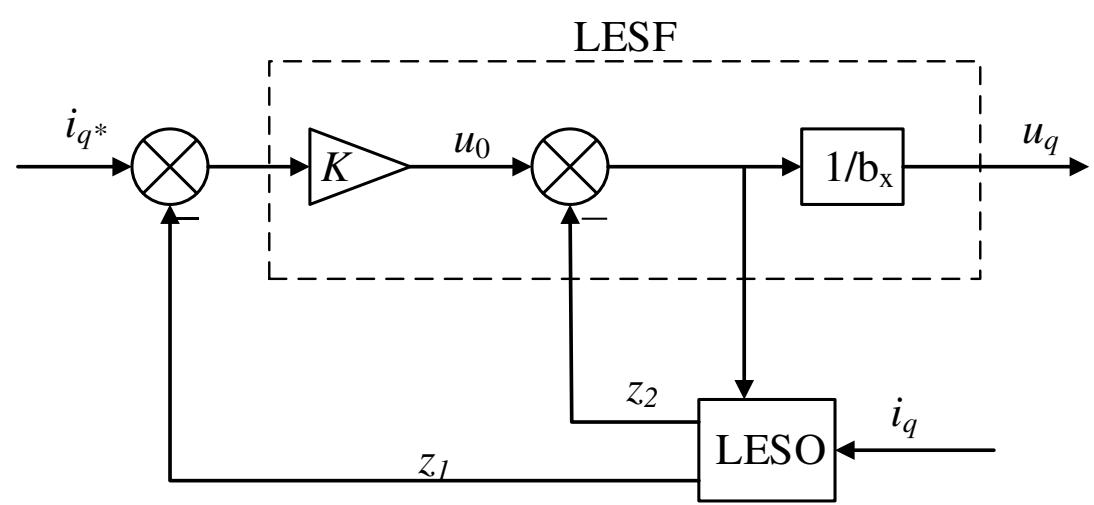

Figure. 5 Current loop q-axis LADRC structure

\subsection{Parameter setting}

The current loop first-order active disturbance rejection control system has 4 parameters that need to be tuned [16], which are $\beta_{1}, \beta_{2}, b_{x, y}$ in LESO and $K$ in LESF. Combining the linear control theory with the bandwidth control idea of Gao [5], we can take $\beta_{1}=2 \omega_{o}, \beta_{2}=\omega_{o}^{2}$, where $\omega_{o}$ is the bandwidth of the observer. During the trial adjustment process, the larger the bandwidth of the linear observer within a certain range, the faster the observation and compensation of disturbances. $K$ is the speed closed loop bandwidth $\omega_{c}$, the general $\omega_{o}=2-8 \omega_{c} . b_{x, y}$ can only be set by debugging. The following experience can be obtained through debugging. When the speed does not reach the rated speed, $b_{x, y}$ may be too small, and should be adjusted appropriately. When the current or speed fluctuates greatly and cannot be stabilized, it indicates that $b_{x, y}$ are too large, and should be adjusted appropriately. If the speed or current is stable after repeated oscillations, it indicates that $b_{x, y}$ are too small and should be increased appropriately. The control variable method should be adopted in the trial adjustment process, and each parameter should be adjusted step by step to make the control result tend to the ideal state.

\section{Experimental simulation analysis}

\subsection{Parameters of motorized spindle}

In this experiment, this paper carries out simulink modeling analysis on the FL170-20-15 high-speed grinding motorized spindle. The main parameters of high-speed motorized spindle are shown in Table 4 . 
Table 4 Partial parameters of motorized spindle

\begin{tabular}{llll}
\hline \multicolumn{1}{c}{ Parameter Name } & values & Parameter Name & values \\
\hline Torque winding resistance $\mathrm{R}_{\mathrm{M}} / \Omega$ & 0.15 & Suspension winding resistance $\mathrm{R}_{\mathrm{B}} / \Omega$ & 1.86 \\
Torque winding inductance $L_{\mathrm{M}} / \mathrm{mH}$ & 2.8 & Suspension winding inductance $L_{\mathrm{B}} / \mathrm{mH}$ & 2.8 \\
Rotational inertia $J /\left(\mathrm{kg} \bullet \mathrm{m}^{2}\right)$ & 0.015 & Air gap length $\delta_{0} / \mathrm{mm}$ & 0.5 \\
Permanent magnet chains $\psi_{f} / \mathrm{Wb}$ & 0.114 & Auxiliary bearing-rotor clearance $\delta_{1} / \mathrm{mm}$ & 0.3 \\
DC voltage $\mathrm{U} / \mathrm{V}$ & 540 & & \\
\hline
\end{tabular}

\subsection{Simulink model diagram}

The fuzzy PI-LADRC combined control model of permanent magnet synchronous motorized spindle is shown in Figure 6 in MATLAB/Simulink:

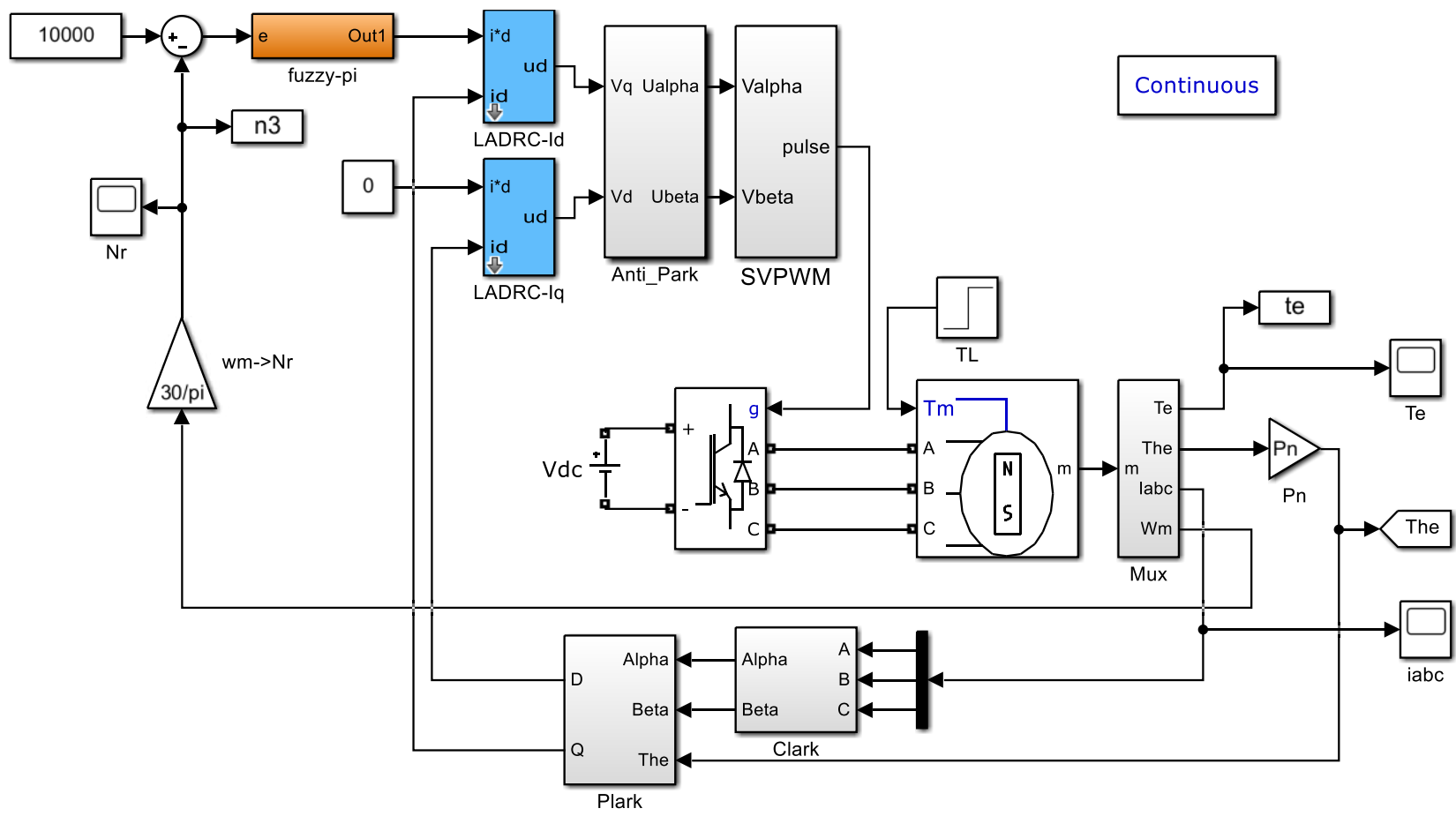

Figure. 6 Model diagram of fuzzy PI-LADRC combined control

\subsection{Result analysis}

In the simulation, to make the comparison more intuitive, the three kinds of control (traditional PI control, fuzzy PI control, fuzzy PI-LADRC combined control) speed charts are put together for comparison. The simulation time is $2.5 \mathrm{~s}$. The rated speed is $10000 \mathrm{r} / \mathrm{min}$, no-load start to rated speed, apply $10 \mathrm{~N}$ step load in 1.6 seconds. The speed curve is shown in Figure 7, where the $\mathrm{X}$ axis is time $\mathrm{t}(\mathrm{s})$, and the $\mathrm{Y}$ axis is speed $\mathrm{n}(\mathrm{r} / \mathrm{min})$. Through the $0.84-0.92 \mathrm{~s}$ partial enlarged view, it is obvious that the time for the fuzzy PI-LADRC to reach the rated speed is shorter than the fuzzy PI control and the traditional PI control, and its response speed is faster. Through the partial enlargement of $1.6-1.75 \mathrm{~s}$, it can be seen that the traditional PI control needs $0.15 \mathrm{~s}$ to return to the steady state value after the sudden load is applied, and the fuzzy PI control needs $0.07 \mathrm{~s}$ to return to the steady state value. Compare the previous two fuzzy PI-LADRC combined control it is almost free from sudden load interference, reflecting its robustness. 


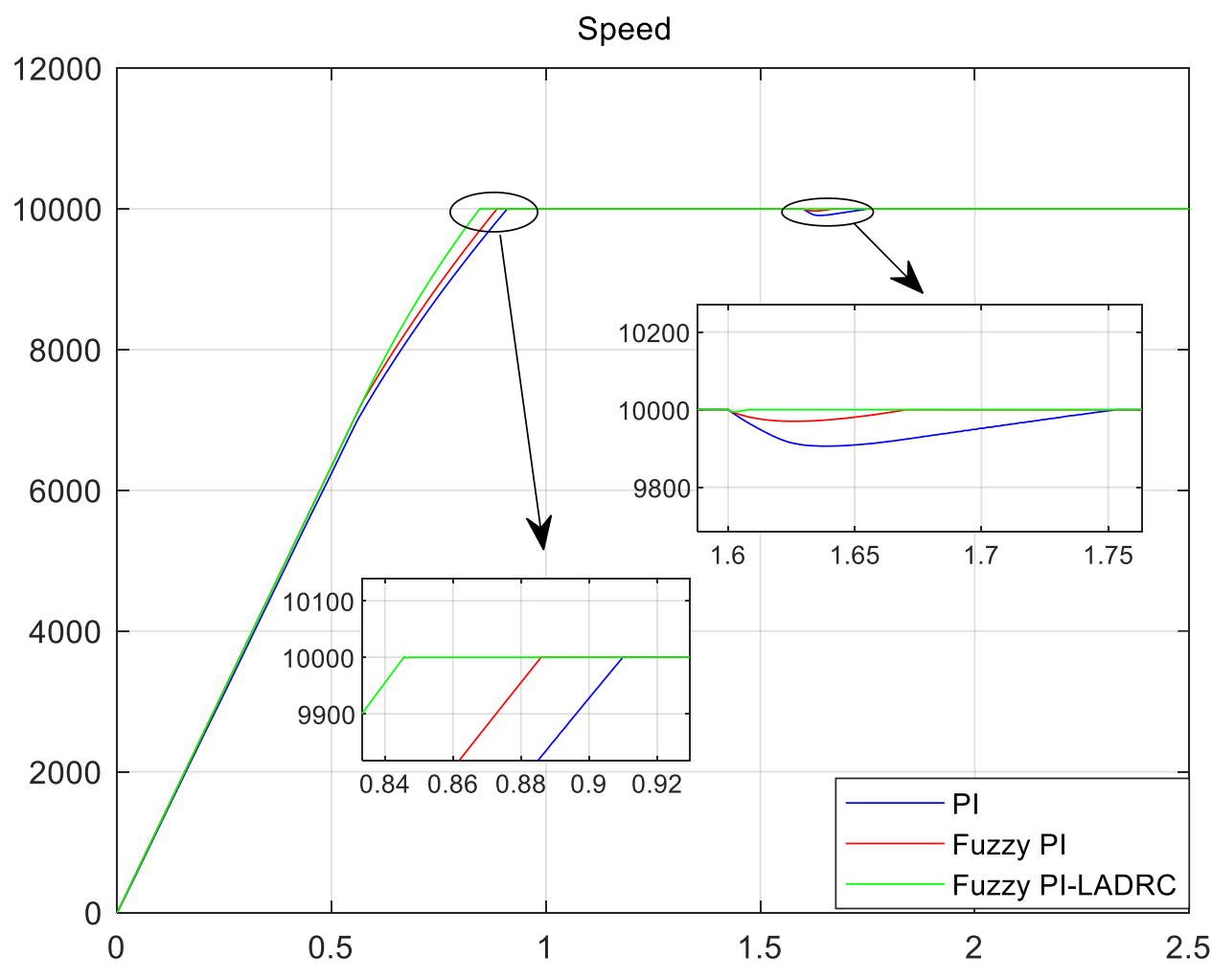

Figure. 7 Speed response curve

It can be seen from Figures 8, 9 and 10 that the traditional PI control has large torque pulsation. Through local amplification of the steady state of no-load operation and the steady state of operation after sudden load, it is found that the torque pulsation is about $\pm 1.2 \mathrm{~N} \cdot \mathrm{m}$, which is anti-interference poor ability. Compared with the traditional PI control, the torque ripple of the fuzzy PI is significantly reduced. The torque ripple only fluctuates within $\pm 0.3 \mathrm{~N} \cdot \mathrm{m}$, but the response is slower after a sudden load. After adopting the fuzzy PI-LADRC combined control, the torque ripple is smaller, the response speed is faster after the sudden loading, and the anti-interference ability is stronger. 


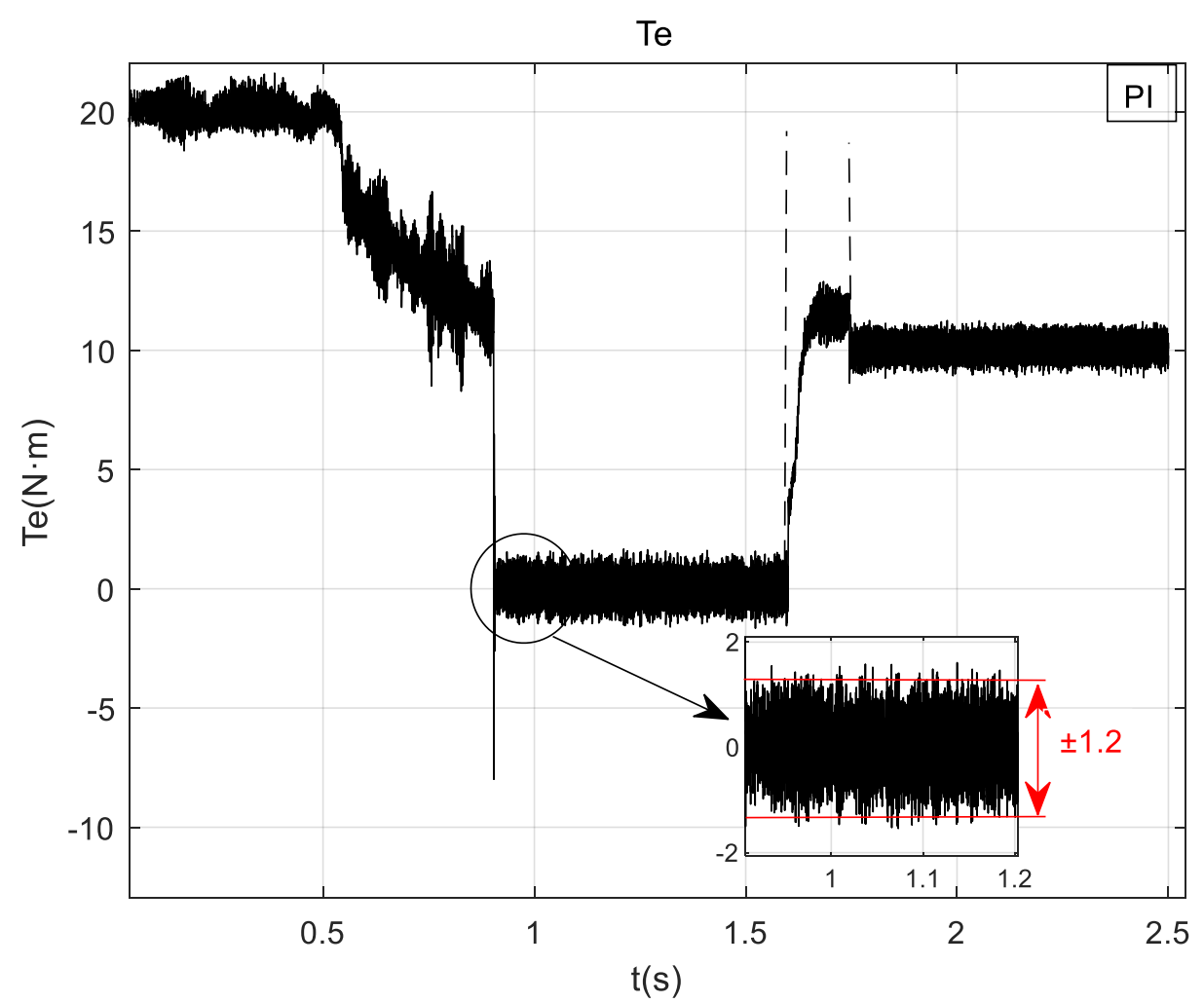

Figure. 8 PI control torque diagram

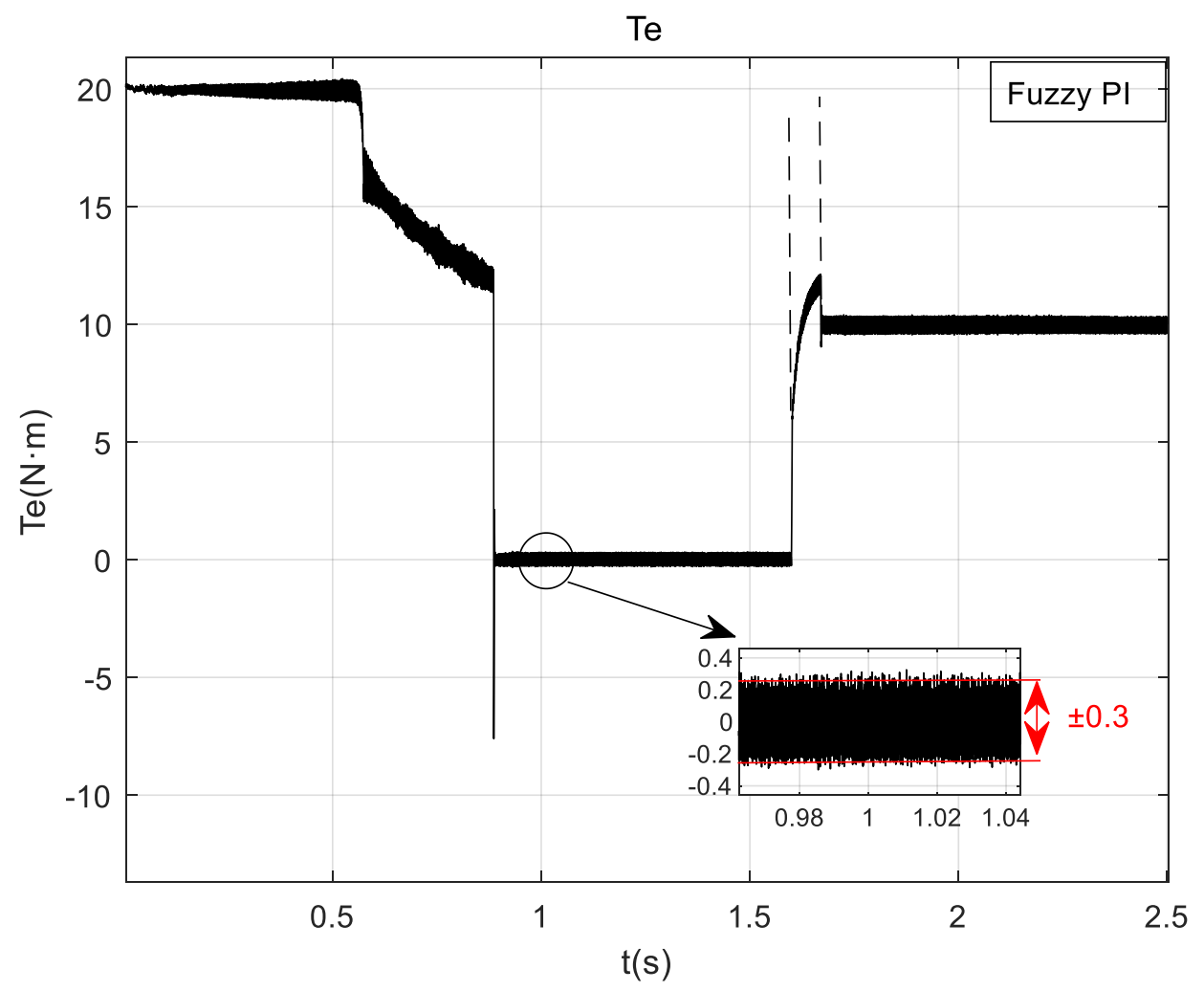

Figure. 9 Fuzzy PI control torque diagram 


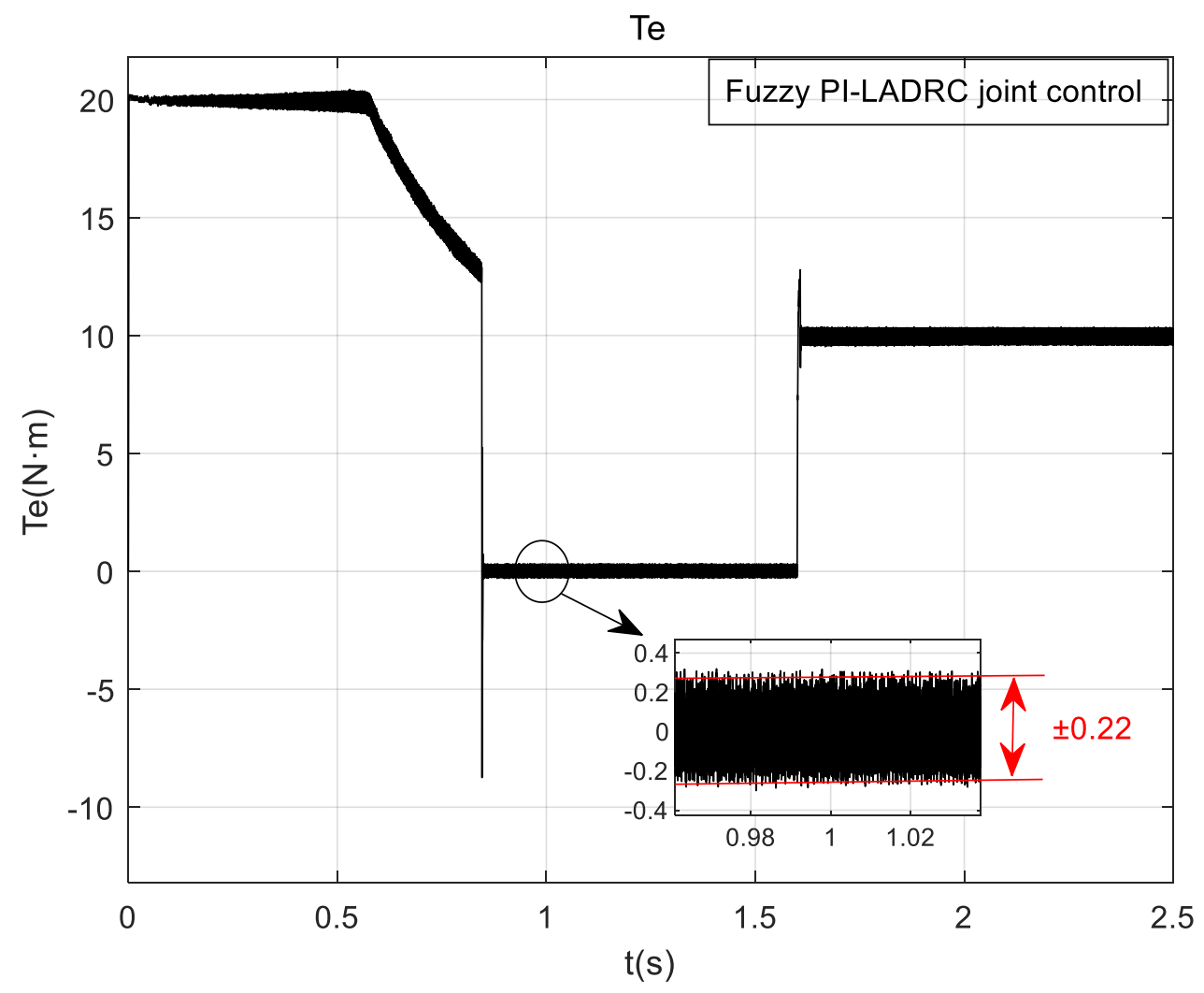

Figure. 10 Fuzzy PI-LADRC combined control torque diagram

From figures 11, 12 and 13, the current of traditional PI control fluctuates greatly, the current distortion is serious, and the response speed is slow after sudden loading. Fuzzy PI control relatively improves the shortcomings of large current fluctuations, but the response speed is slower after sudden load. After adopting fuzzy PI-LADRC combined control, the current fluctuation is small, and the response speed is fast after sudden load. 


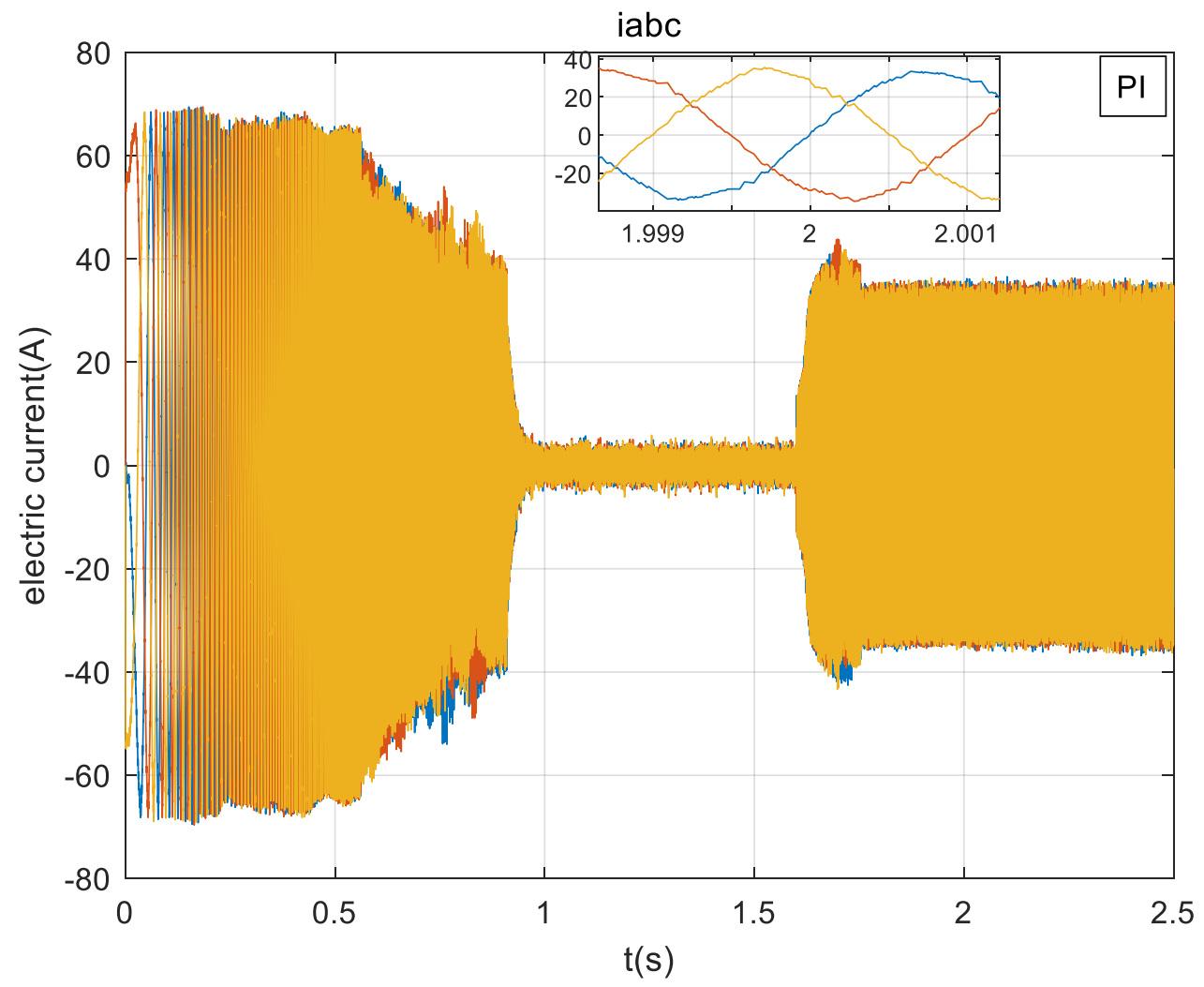

Figure. 11 PI control three-phase current diagram

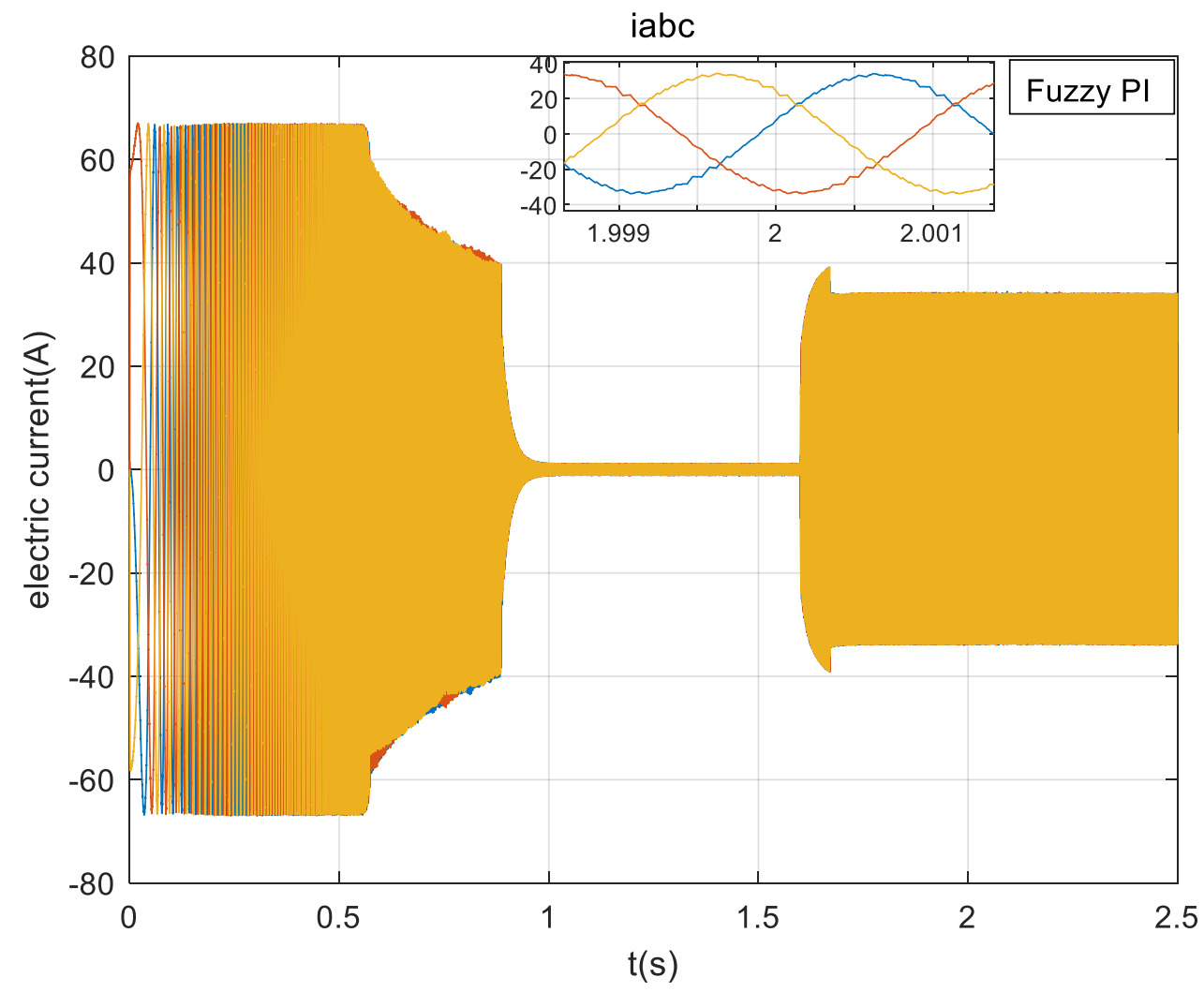

Figure. 12 Fuzzy PI control three-phase current diagram 


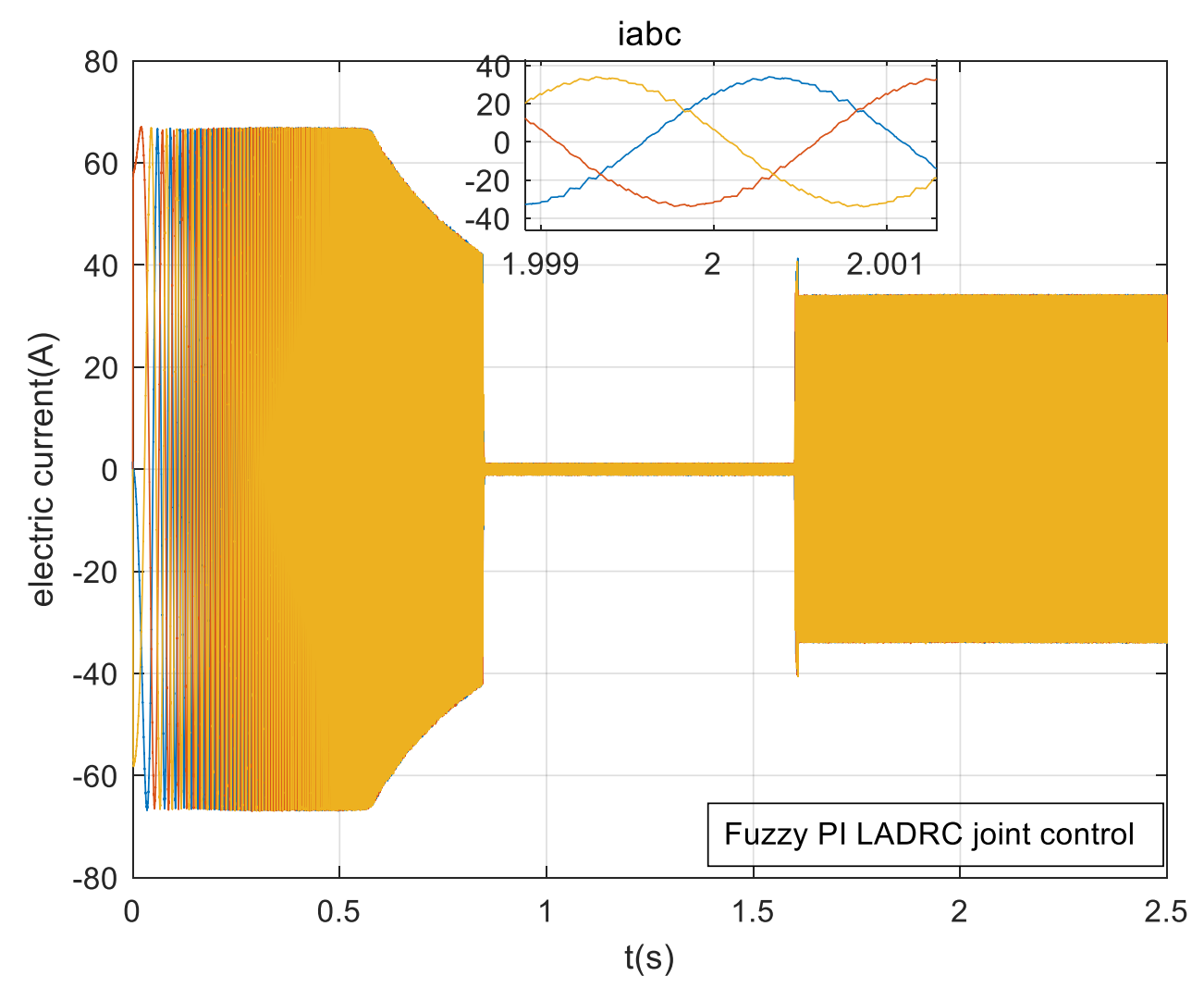

\section{Conclusion}

Figure. 13 Fuzzy PI-LADRC combined control three-phase current diagram

In this paper, a fuzzy PI-LADRC combined control strategy is proposed and applied to high-speed motorized spindle, and a vector control method with double closed loops of current and speed is adopted. The functions of speed loop and current loop are analyzed, and the speed loop and current loop are designed respectively according to the problems in high-speed operation of motorized spindle. The simulation results show that the control system effectively improves the dynamic response ability and anti-interference ability of motorized spindle; The torque ripple under high-speed operation condition is reduced; It has certain adaptability and robustness. Because of the high-speed motorized spindle has the characteristics of multivariable and strong coupling, it is necessary to study the intelligent algorithm more deeply to make the control effect better.

\section{Acknowledgement}

This work was supported by National Natural Science Foundation of China (No. 52005229), and Qing Lan Project of JiangSu Province (No. KYQ20004), and Major Project of Natural Science Research in Universities of JiangSu (No. 19KJA510001).

\section{Conflicts of Interest}

The authors declare that they have no conflicts of interest. 


\section{References}

[1] Numerical control machine tool functional parts optimization design selection application manual. High-speed motorized spindle catalogue/edited by Chengying Liu. Beijing: China Machine Press, 2018.4.

[2] Jingqing Han. Active Disturbance Rejection Control Technology Estimation and Compensation Control Technology for Uncertain Factors. National Defense Industry Press, 2008.

[3] Kai Zhou, Yancheng Sun, Xudong Xu, Da Yan. Auto disturbance rejection control speed regulation strategy of permanent magnet synchronous motor[J]. Journal of Electrical Machines and Control,2018,22(02):57-63.

[4] Bin Sun, Haixia Wang, Tao Su, Chunyang Sheng, Xiaoran Lv. Design and Parameter Tuning of Nonlinear Active Disturbance Rejection Controller for Permanent Magnet Synchronous Motor Speed Control System[J]. Proceedings of the Chinese Society for Electrical Engineering,2020,40(20):6715-6726.

[5] Haiyu Gao, Junyou Yang, Xiaoguang Zhang, Jia Cui. Improved active disturbance rejection control strategy for permanent magnet synchronous elevator door machine[J]. Journal of Harbin Institute of Technology,2018,50(09):191-198.

[6] Zhiqiang Gao. (2003). Scaling and Parameterization Based Controller Tuning. Proceedings of the American Control Conference.6.4989-4996. 10.1109/ACC.2003.1242516.

[7] W. Chang, M. Wang, H. Yang and W. Yan, "Improved Rotor Position Detection Speed Based on Optimized BP Neural Network for Permanent Magnet Synchronous Motor," 2019 5th International Conference on Control, Automation and Robotics (ICCAR), Beijing, China, 2019, pp. 505-510, doi: 10.1109/ICCAR.2019.8813468.

[8] Zhu P, Chen Y, Li M. Terminal sliding mode control of permanent magnet synchronous motor based on the reaching law. Proceedings of the Institution of Mechanical Engineers, Part I: Journal of Systems and Control Engineering. 2020;234(7):849-859. doi:10.1177/0959651819893170.

[9] Lei Yuan, Bingxin $\mathrm{Hu}$, keyin Wei, Shu Chen. Control principle and MATLAB simulation of modern permanent magnet synchronous motor [M]. Beijing: Beijing University of Aeronautics and Astronautics Press, 2016, 3

[10] Y. Zhou and S. Chen, "Fuzzy Control for Treadmill Permanent Magnet Synchronous Motor Speed System," 2020 5th International Conference on Advanced Robotics and Mechatronics (ICARM), Shenzhen, China, 2020, pp. 646-651, doi: 10.1109/ICARM49381.2020.9195339.

[11] Wentao Shan, Xin Wang. PMSMS field weakening speed regulation control strategy based on fuzzy sliding mode switching control[J]. Journal of Vibration and Shock,2020,39(04):222-228.

[12] Weiran Wang, Jiaxin Wu, Yi Zahng, Haifeng Wei, Huilin Ge. Permanent magnet synchronous motor fuzzy self-tuning adaptive integral backstepping control[J]. Transactions of the Chinese Society of Electrical Engineering,2020,35(04):724-733.

[13] Fuxin Wang, Shijie Gao. PMSM current loop control algorithm based on the theory of active disturbance rejection[J]. Journal of Shanghai Institute of Ship and Transportation,2018,41(03):24-28.

[14] Yang Xie, Renhua Jiang, Yayun Liu. Design of airborne radar servo system based on cascaded first-order active disturbance rejection controller[J]. Micro Motor,2018,51(05):36-42.

[15] Chunqiang Liu, Guangzhao Luo, Zhe Chen, Wencong Tu, Measurement delay compensated LADRC based current controller design for PMSM drives with a simple parameter tuning method, ISA Transactions, Volume 101,2020, 482-492.

[16] Yuenan Zeng, Bin Zhou, Lei Zheng, Houjian Lin. Design of first-order linear ADRC for permanent magnet synchronous motor [J]. Control Engineering, 2017, 24 (09): 1818-1822. 
Figures

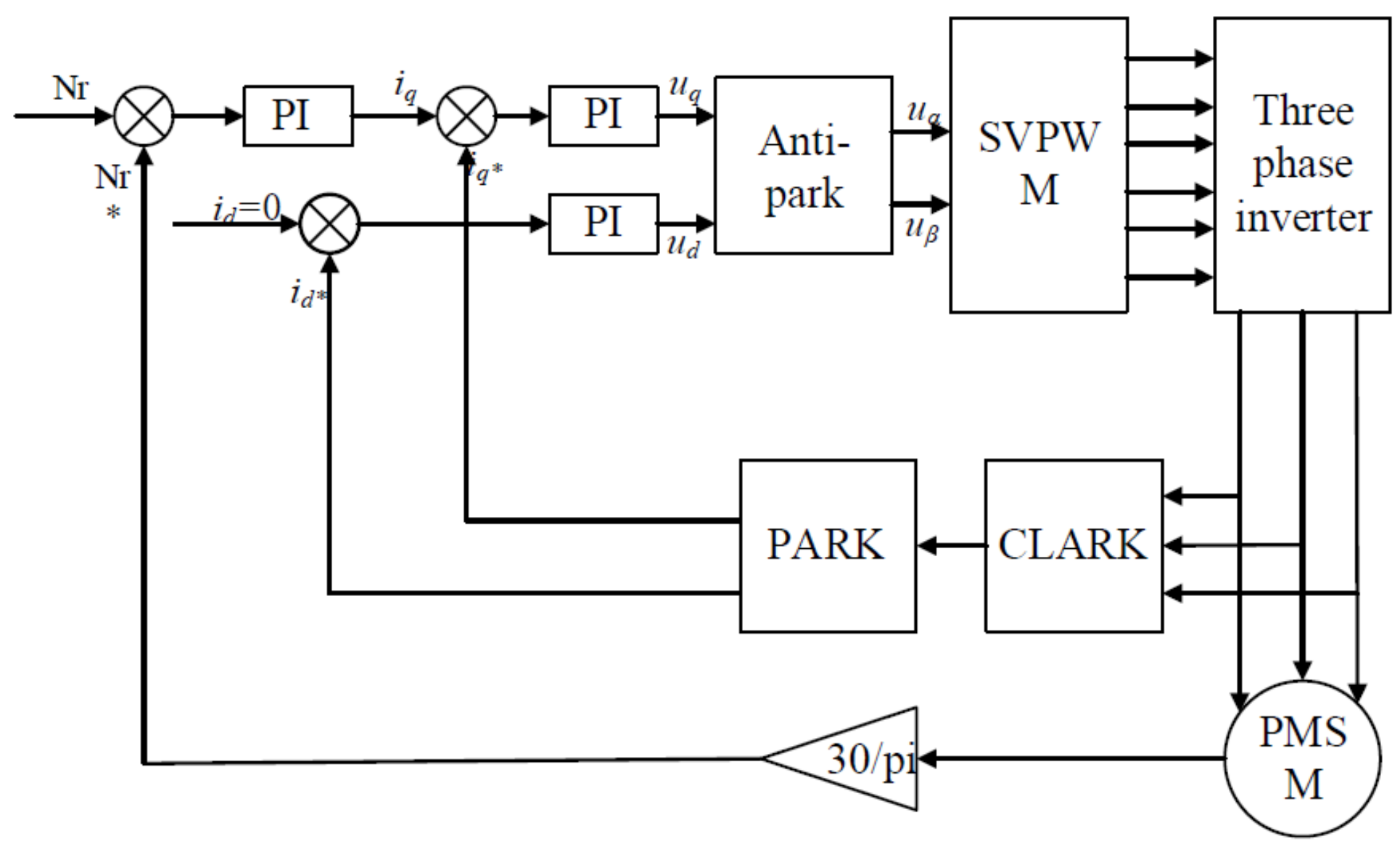

Figure 1

Traditional PI control system block diagram

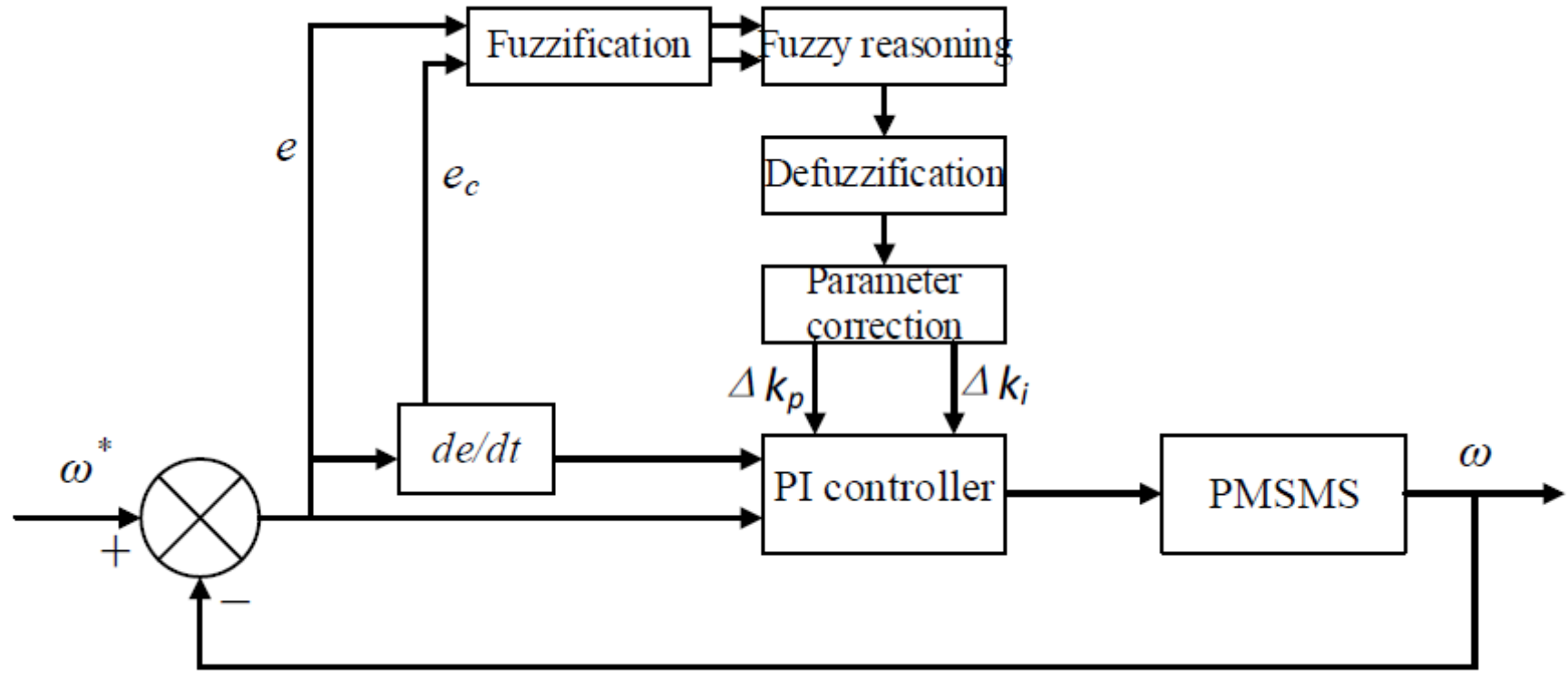

Figure 2 
Structure block diagram of fuzzy controller

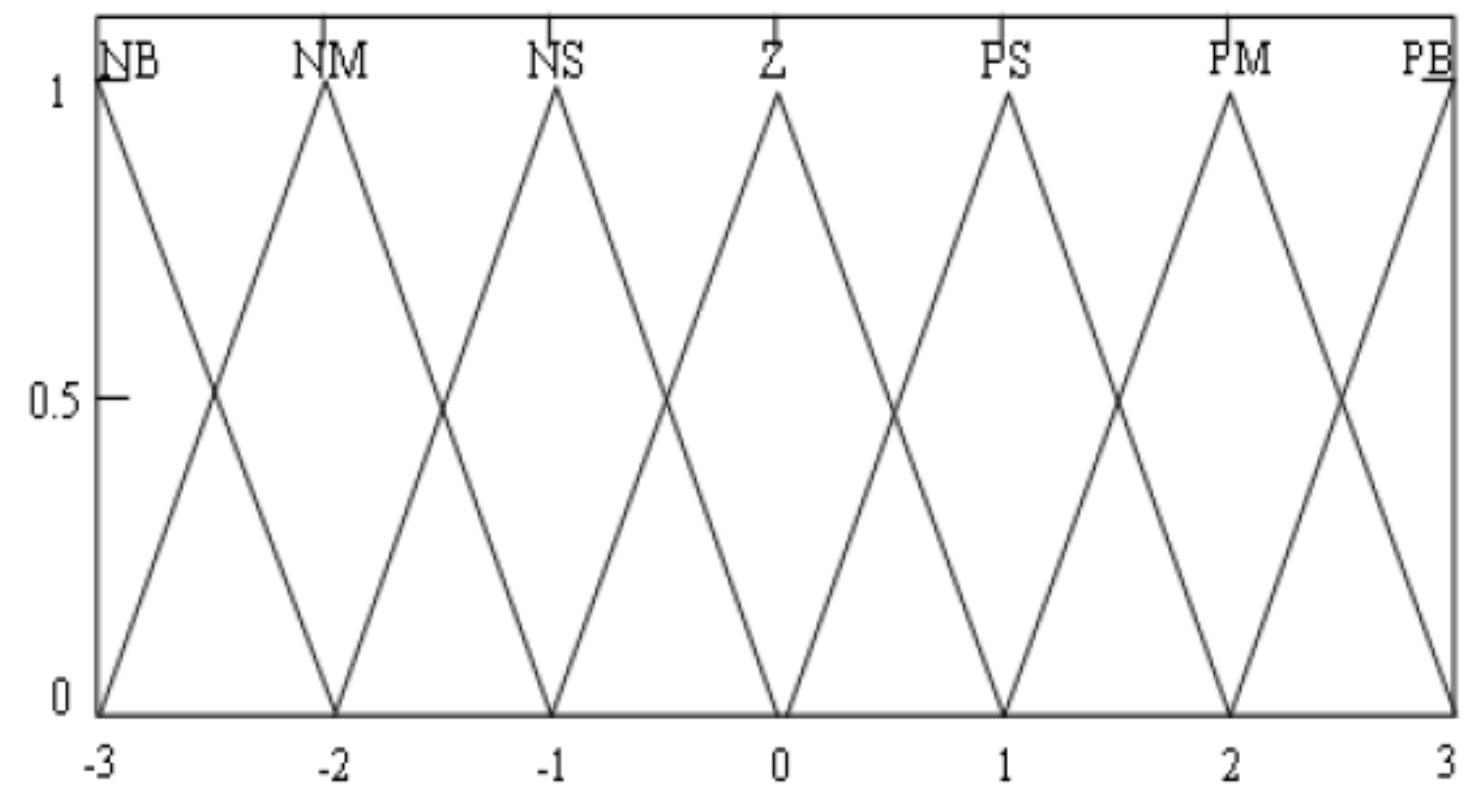

Figure 3

Membership function diagram

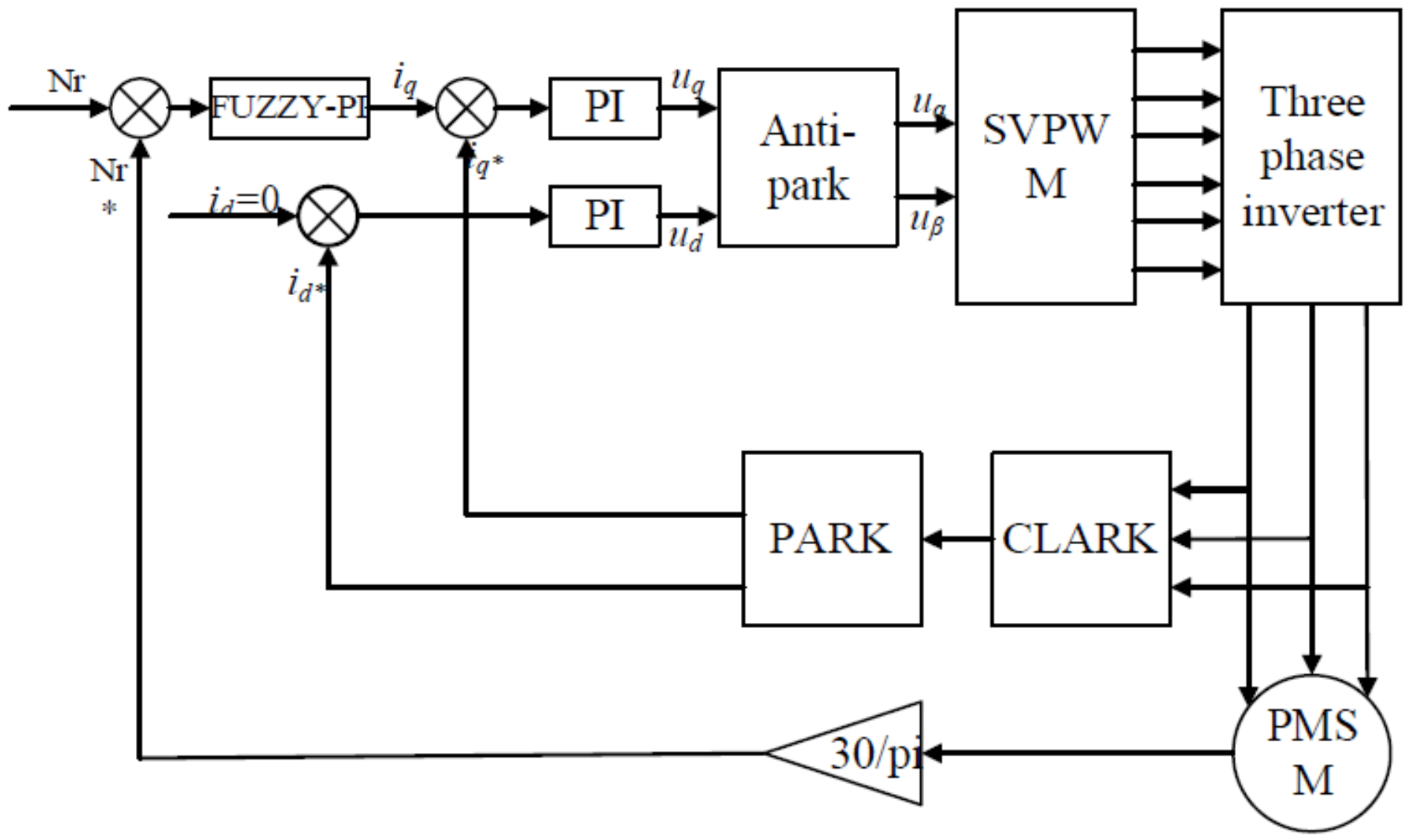

Figure 4

Fuzzy PI control system block diagram 


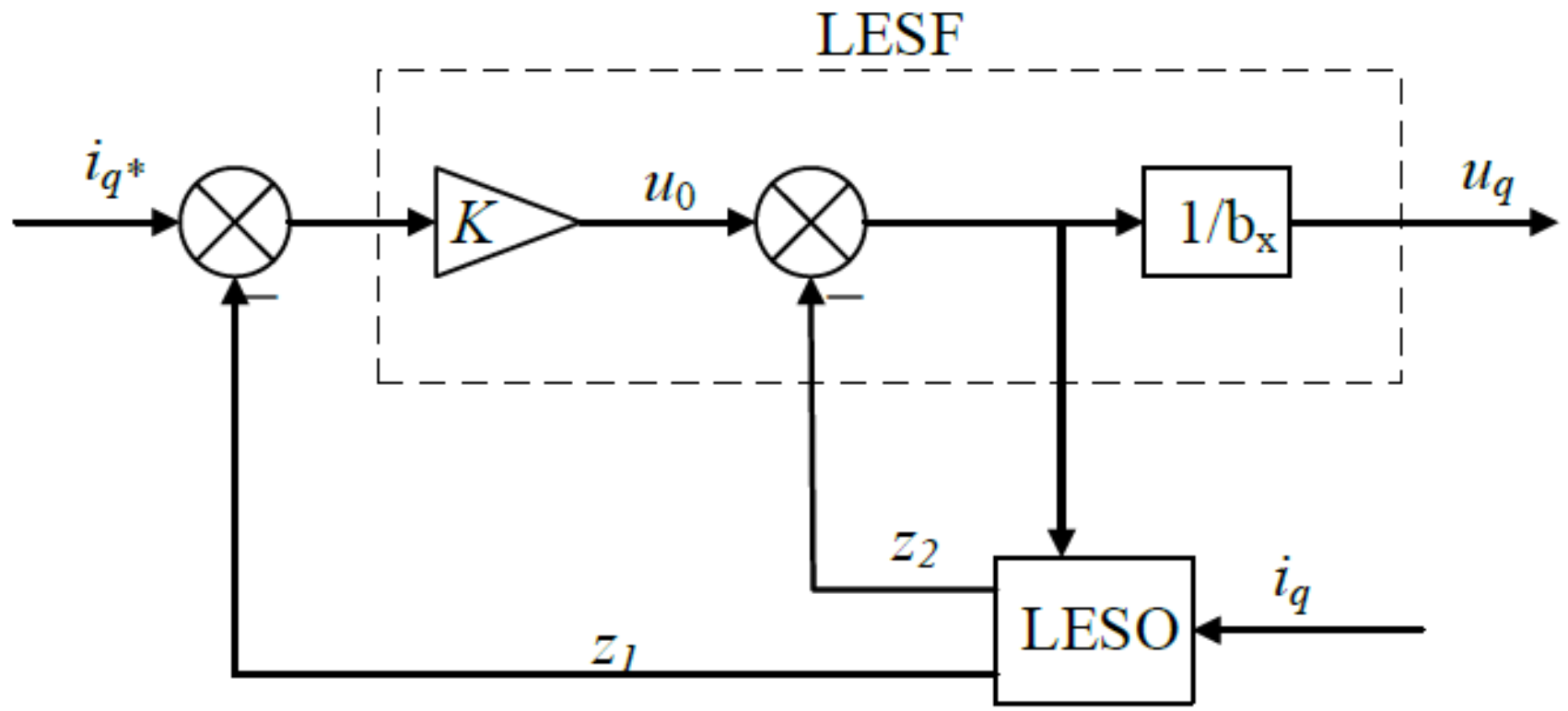

Figure 5

Current loop q-axis LADRC structure

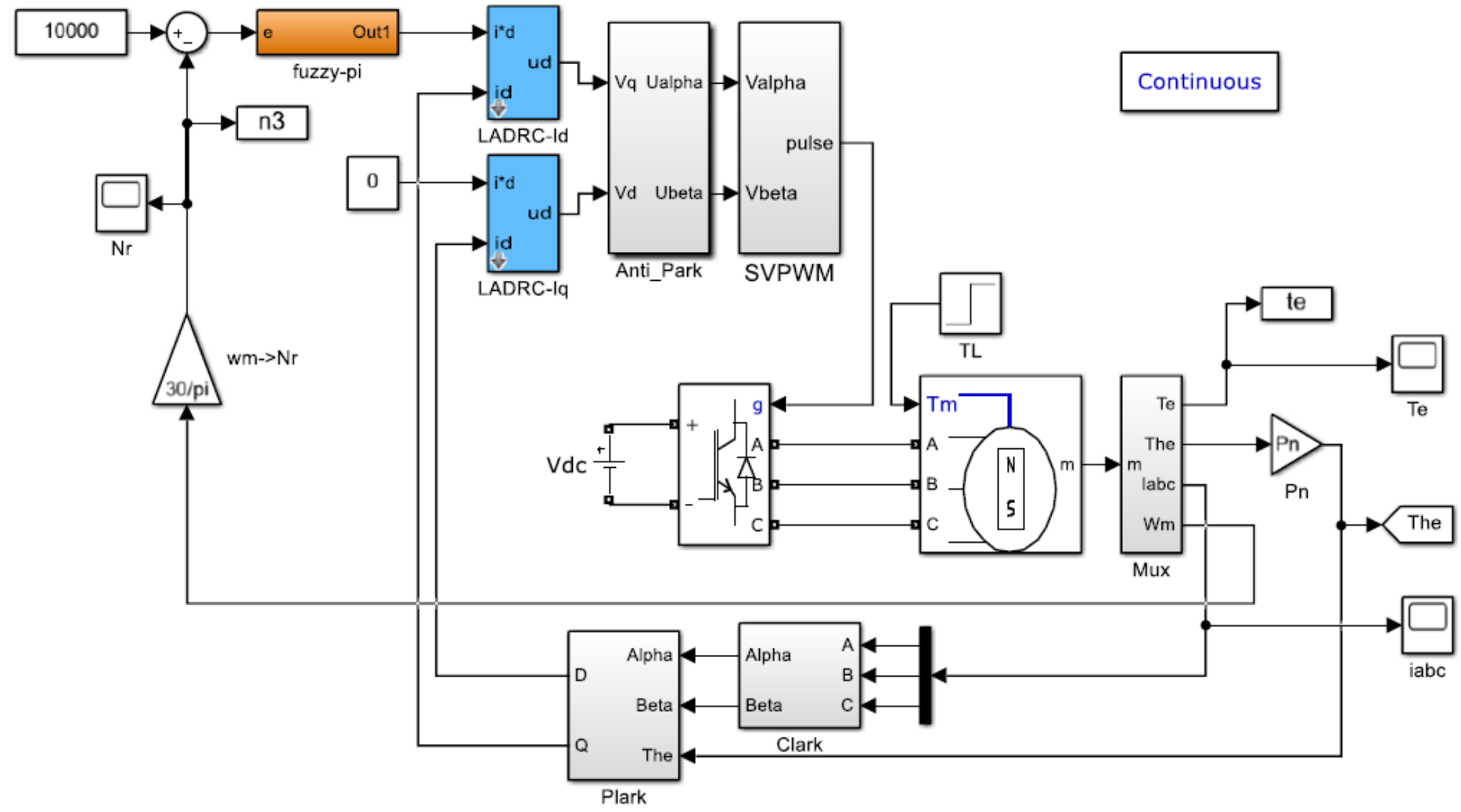

Figure 6

Model diagram of fuzzy PI-LADRC combined control 


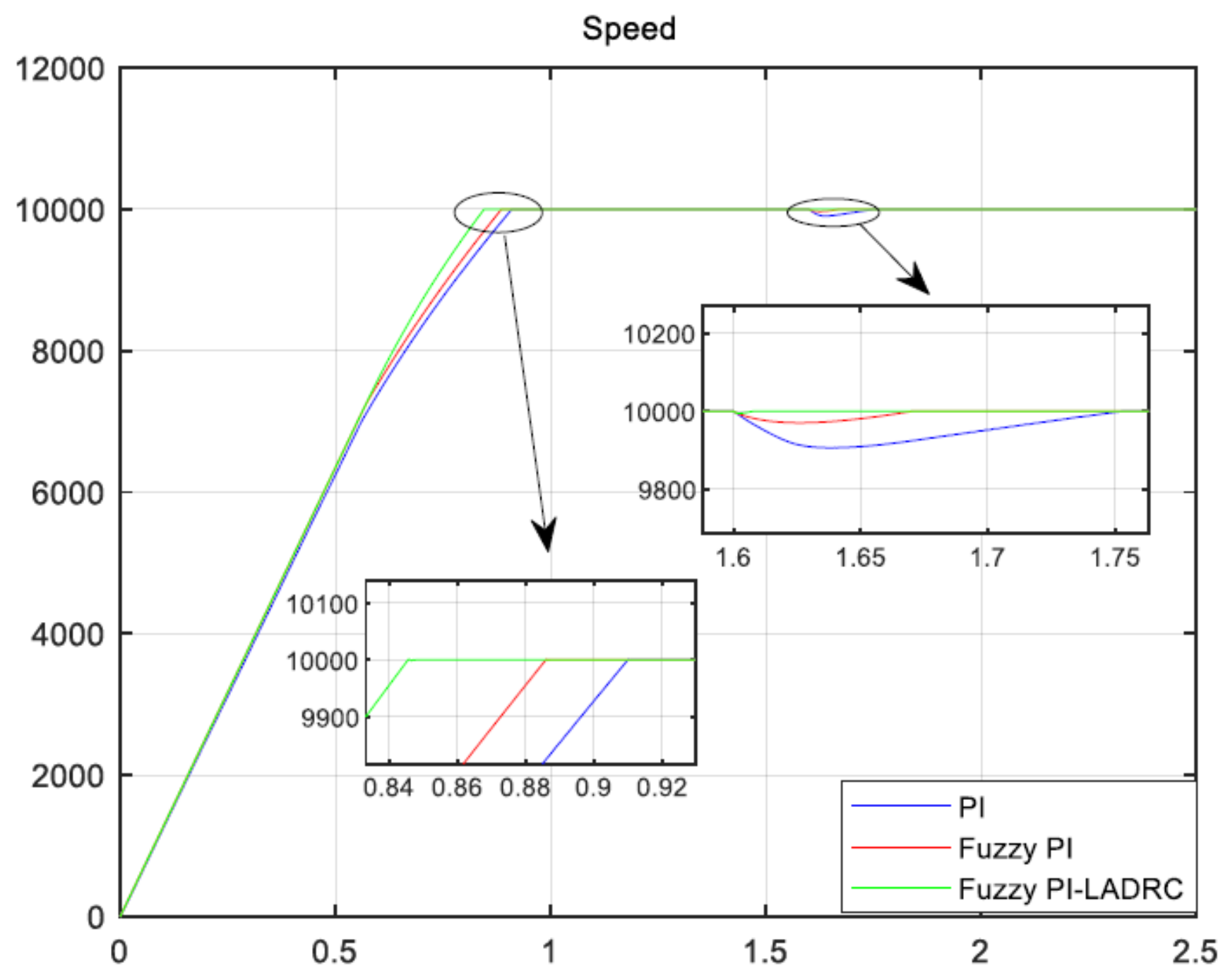

Figure 7

Speed response curve 
$\mathrm{Te}$

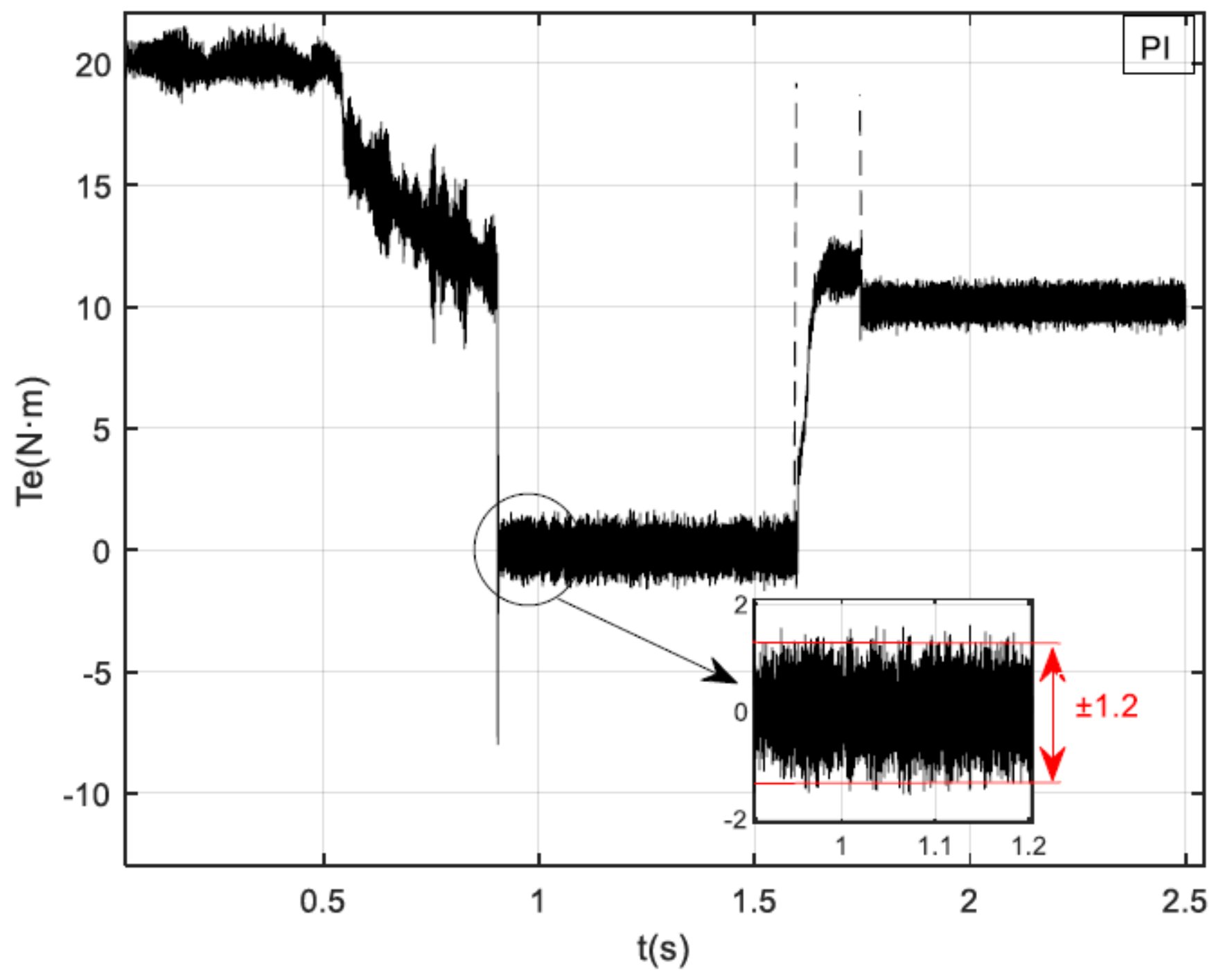

Figure 8

PI control torque diagram 


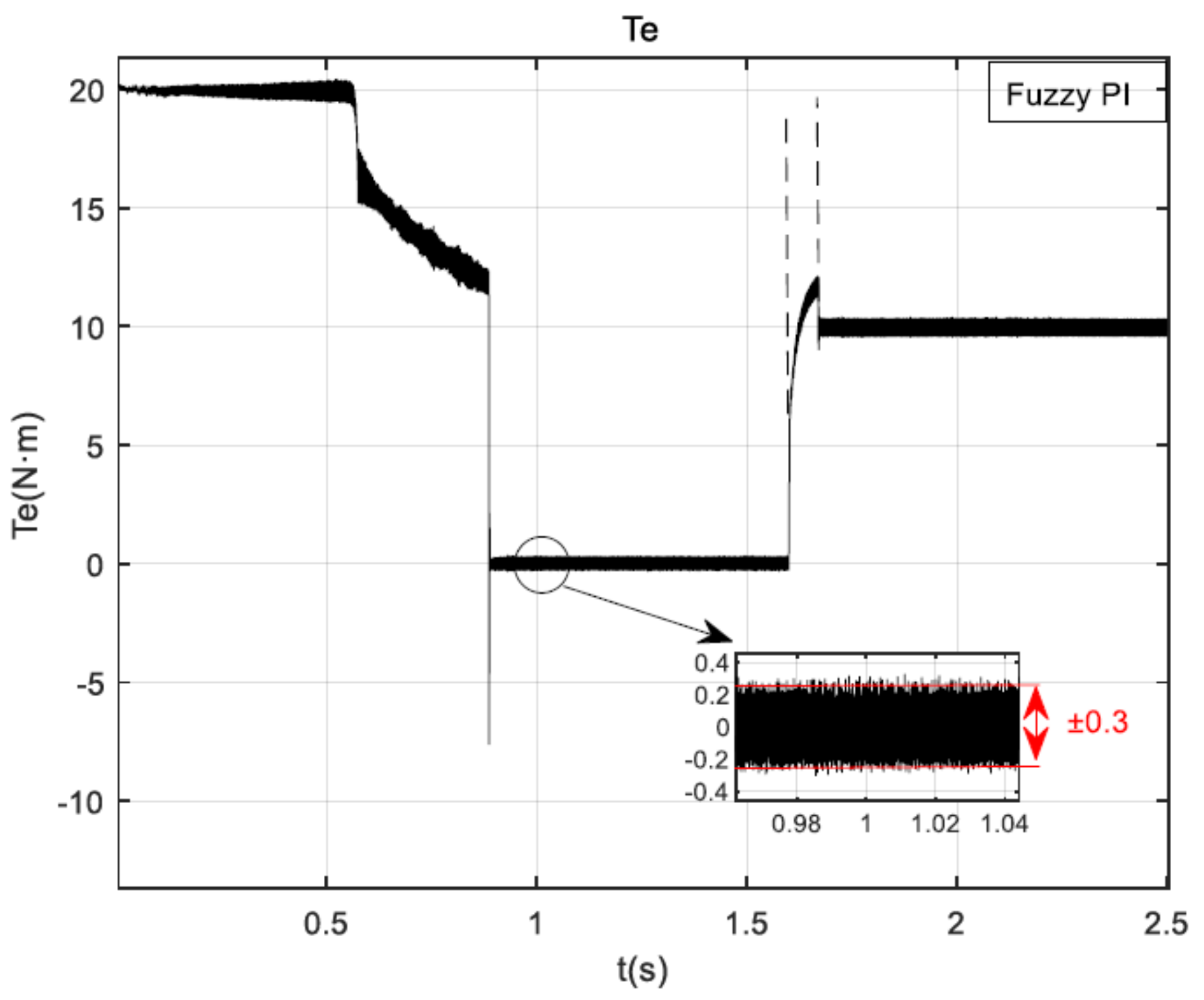

Figure 9

Fuzzy PI control torque diagram 


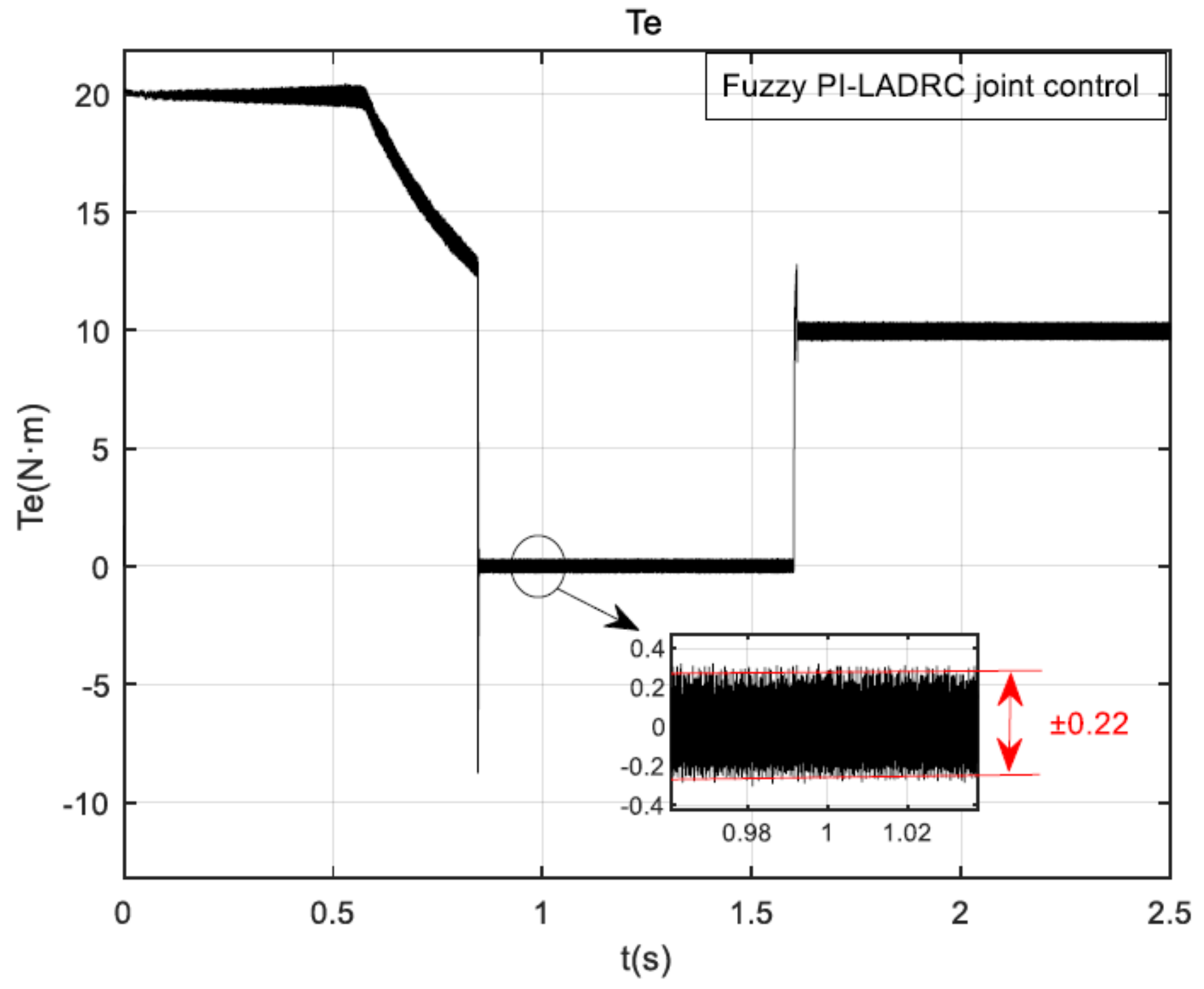

Figure 10

Fuzzy PI-LADRC combined control torque diagram 


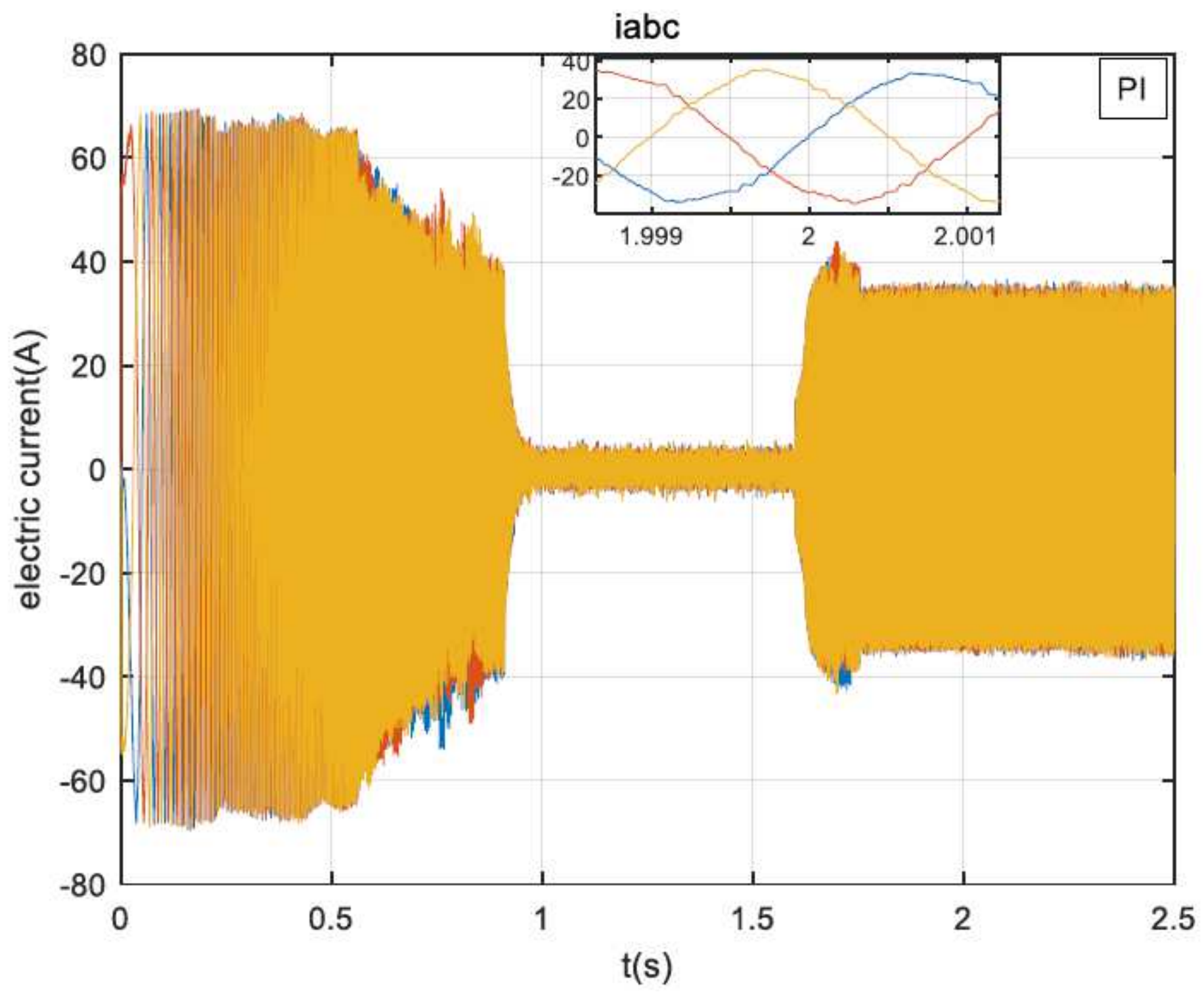

Figure 11

PI control three-phase current diagram 


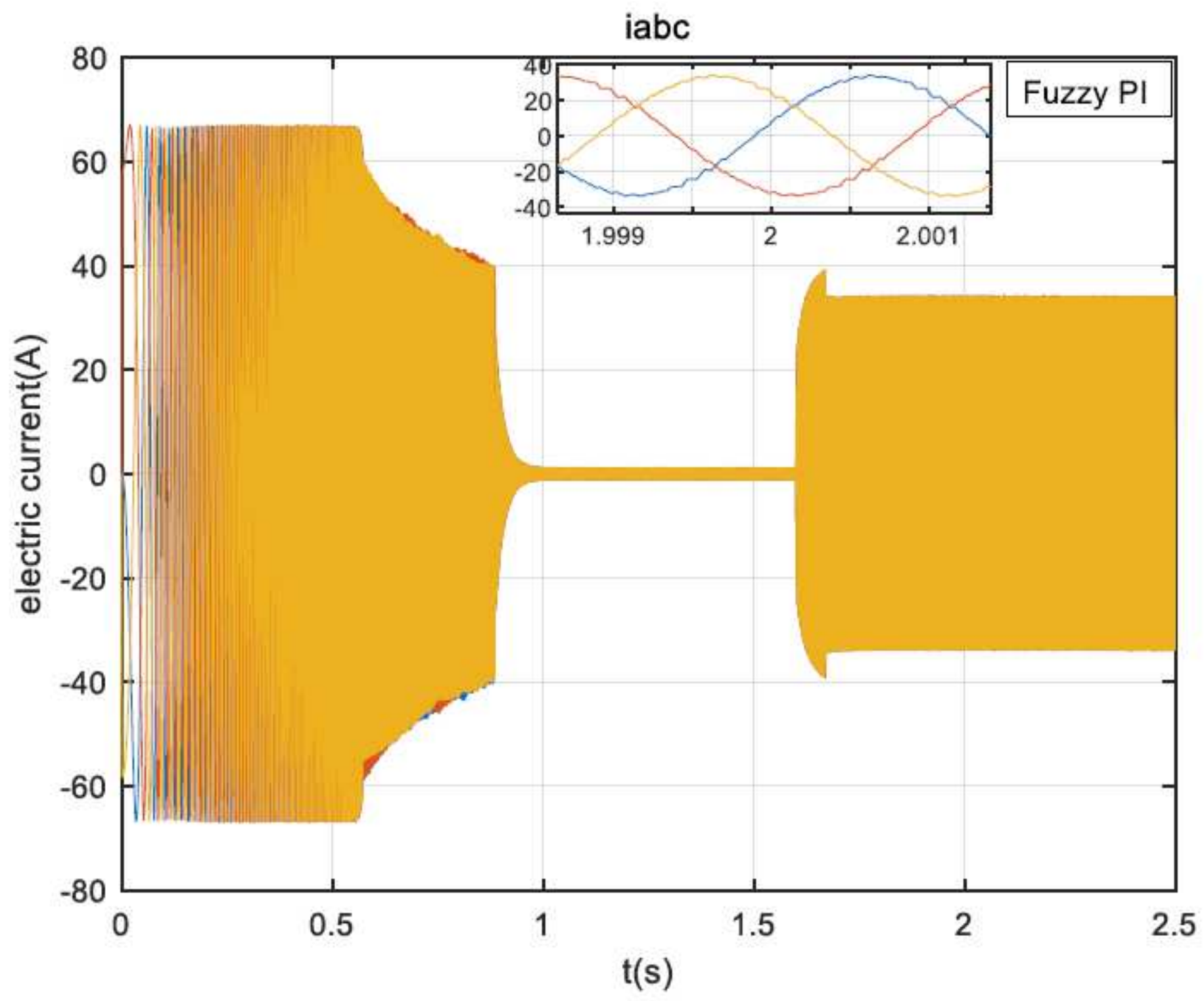

Figure 12

Fuzzy PI control three-phase current diagram 


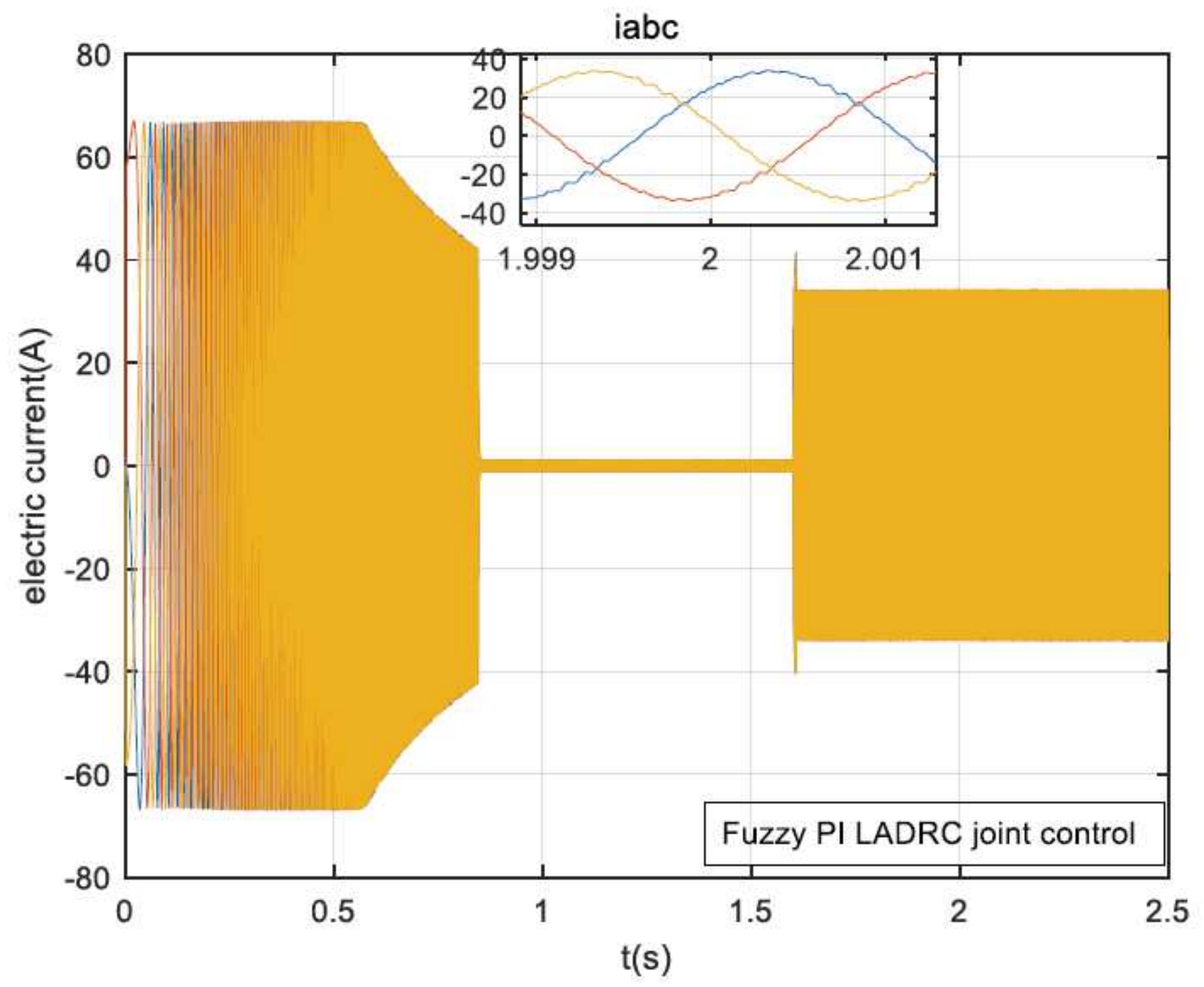

Figure 13

Fuzzy PI-LADRC combined control three-phase current diagram 